\title{
LA NECRÓPOLIS MEGALÍTICA DE LOS MOLARES: ESTUDIO LÍTICO PRELIMINAR DE LA INDUSTRIA TALLADA Y PULIMENTADA DE CAÑADA REAL Y EL PALOMAR. ANÁLISIS DE CARACTERIZACIÓN DE LA MATERIA PRIMA, MORFOLÓGICO, TÉCNICO Y TIPOMÉTRICO
}

\author{
THE MEGALITHIC NECROPOLIS OF LOS MOLARES: PRELIMINARY STUDY OF THE CARVED \\ AND POLISHED LITHIC INDUSTRY FROM CAÑADA REAL AND EL PALOMAR. MORPHOLOGIC, \\ TECHNICAL AND TYPOMETRIC ANALYSIS AND RAW MATERIALS CHARACTERIZATION
}

\author{
por \\ Rosario CABrero García * \\ MARÍA VALVERDE LASANTA ** \\ EMILIO PASCUAL MARTÍNEZ ${ }^{* *}$ \\ Diego Oliva Alonso *** \\ EZEQUIEL GÓMEZ MURGA ${ }^{* * * * *}$
}

RESUMEN Presentamos aquí un análisis preliminar de la industria lítica tallada y pulimentada de los dólmenes de Cañada Real y El Palomar (Los Molares, Sevilla), como paso previo a la publicación conjunta de ambos monumentos funerarios que, pese a haber sido excavados en momentos distintos, pertenecieron a una necrópolis megalítica de la primera mitad del IV milenio a.n.e., junto con otros hoy desaparecidos, todos ellos de igual tipología.

ABSTRACT Here we present a preliminary analysis of the carved and polished lithic industry of the dolmens of Cañada Real and El Palomar (Los Molares, Sevilla), as a previous step to the joint publication about both funerary monuments. Although they were excavated at different moments, both of them belonged to a megalithic necropolis of the first half of IV millennium B.C. These monuments, along with some others that are disappeared nowadays, show the same typology.

\footnotetext{
* Profesora Titular del Dpto. de Prehistoria y Arqueología de la Universidad de Sevilla. Dirección: C/ Doña María de Padilla s/n, CP 41004 - Sevilla. Telf. 954551 411.e-mail: cabrero@us.es

** Lda. en Prehistoria. Becaria de investigación desde 1989 a 1992 del Área de Prehistoria de la Universidad de Cádiz. Dirección: Biblioteca Central, Campus Universitario s/n, CP 10071 - Cáceres. Telf. 927257 090. e-mail: maria.valverde@jara.unex.es

*** Catedrático de Geología. Dpto. de Geología, Universidad de Huelva. Dirección: Avda. de las Fuerzas Armadas s/n, CP 21071 - Huelva. Telf. 959019809.

**** Conservador. Museo Arqueológico de Sevilla. Dirección: Pabellón de Bellas Artes, Plaza de América s/n, CP 41003. Telf. 954232401 .

***** Licenciado en Historia. Universidad de Sevilla. Dirección: c/ Castilla la Vieja 81. CP 41700 - Dos Hermanas (Sevilla). Telf. 954729 594. e-mail: egomezmurga@yahoo.es
} 


\begin{abstract}
Palabras claves Megalitismo, industria lítica, IV milenio a.C., Los Molares (Sevilla).
Key words

Megalithism, lithic industry, IV millennium B.C., Los Molares (Sevilla).
\end{abstract}

En los monumentos megalíticos de Cañada Real y El Palomar, situados en la mitad meridional occidental de la Península Ibérica, en la comarca de la campiña sevillana, en el pueblo de Los Molares (Fig. 1), se encontró una muestra importante de industria lítica que hoy damos a conocer, como paso previo a su presentación conjunta con los restantes elementos que nos han llegado, representativos de unas formaciones sociales que hemos elegido como objeto de estudio, y que vivieron en la comarca citada entre el IV y III milenios a.n.e.

$\mathrm{Al}$ mencionar los restantes elementos que nos han llegado, nos referimos tanto a los procedentes de la necrópolis megalítica de Los Molares, como a los del poblado calcolítico de Amarguillo II, algo alejado del cementerio citado (Cabrero 1986: 180-185; Cabrero 1987: 276-277), y de posterior cronología, pero que nos permite conocer el modo de vida de unas poblaciones que vivieron en este lugar en momentos sucesivos y no muy distantes cronológicamente; lo cual consideramos de gran interés.

Para estos monumentos megalíticos tenemos una fecha de ${ }^{14} \mathrm{C}$ de $4930 \pm 70$ B.P. $(3810-3630 \text { a.n.e. })^{1}$, obtenida a partir del análisis de restos humanos encontrados en El Palomar, que ha sido realizada en el laboratorio Beta Analytic Inc. (Miami, USA) (Cabrero et alii 1993: 131-141). Las características básicas del suelo que envuelve a los restos óseos de nuestra zona, han propiciado que éstos no se hayan visto sometidos a la fuerte degradación química que se ha puesto de manifiesto en suelos con un $\mathrm{pH}$ más ácido que, llegando con mayor facilidad al interior del hueso, parece provocar una gran alteración radiocarbónica del colágeno (Nieto et alii 2002: 189-192). No en vano, los restos óseos de Cañada Real han sido puestos como ejemplo de muestras muy poco degradadas por los procesos edafoquímicos (Pecero y Guijo 1998: 191-216).

Cuando aludimos a una muestra importante de industria lítica, no lo hacemos pensando en su aspecto cuantitativo, dado que la muestra no es muy amplia; pero sí cualitativo, por motivos fácilmente deducibles relacionados con el modo de producción de la sociedad que los generó; clave, por lo tanto, para entender los procesos económicos y las relaciones sociales de la misma.

La investigación, en su conjunto, se está realizando en los diferentes proyectos que la primera de las firmantes de este artículo dirige y/o colabora en el suroeste peninsular antes mencionado (Cabrero 1993: 367-371; Cabrero y otros 1991: 901 $)^{2}$, dentro del marco interdisciplinar que estos estudios requieren. Para la determinación de la materia prima, en el caso concreto de la industria lítica aquí recogida, se ha utilizado la morfoescopía ${ }^{3}$.

El sepulcro conocido como Dolmen de Cañada Real (Fig. 2), fue descubierto en 1967, al abrir los cimientos para una urbanización en el pueblo de Los Molares. Excavado por Juan de Mata Carriazo y Arroquia, junto con un equipo de profesores y alumnos de la Facultad de Filosofía y Letras de la Universidad de Sevilla, de él se conocen algunas noticias que fueron publicadas por el director de la excavación arqueológica (Carriazo 1974: 152-154), aunque dicha publicación carecía de toda documentación gráfica. El sucinto croquis de la planta de la tumba que aquí se presenta, fue realizado por Rosario Cabrero García cuando recopilaba datos para la elaboración de su tesis doctoral hacia 1979 (Cabrero 1988); pero el estado de deterioro del sepulcro era tan grande que no permitió precisar más ${ }^{4}$.

1. 3775-3648 a.n.e. según la calibración basada en INTCAL98.

2. Y la colaboración en el Proyecto de Investigación Geoarqueológico de la Minería Antigua Ligado Interregionalmente al Occidente Mediterráneo, III milenio a.n.e. (PIGMALIOM III Milenio a.n.e.), dirigido por Francisco Nocete Calvo. Proyectos de Investigación Programa Sectorial de Promoción General del Conocimiento, Ministerio de Educación y Cultura. Dirección General de Enseñanza Superior e Investigación Científica.

3. Actualmente se están realizando sobre determinados artefactos, análisis más detallados, desde el punto de vista mineralógico y geoquímico.

4. Estaba lleno de escombros y otras basuras, casi destruido y con una vivienda junto a él que dificultaba el acceso. 

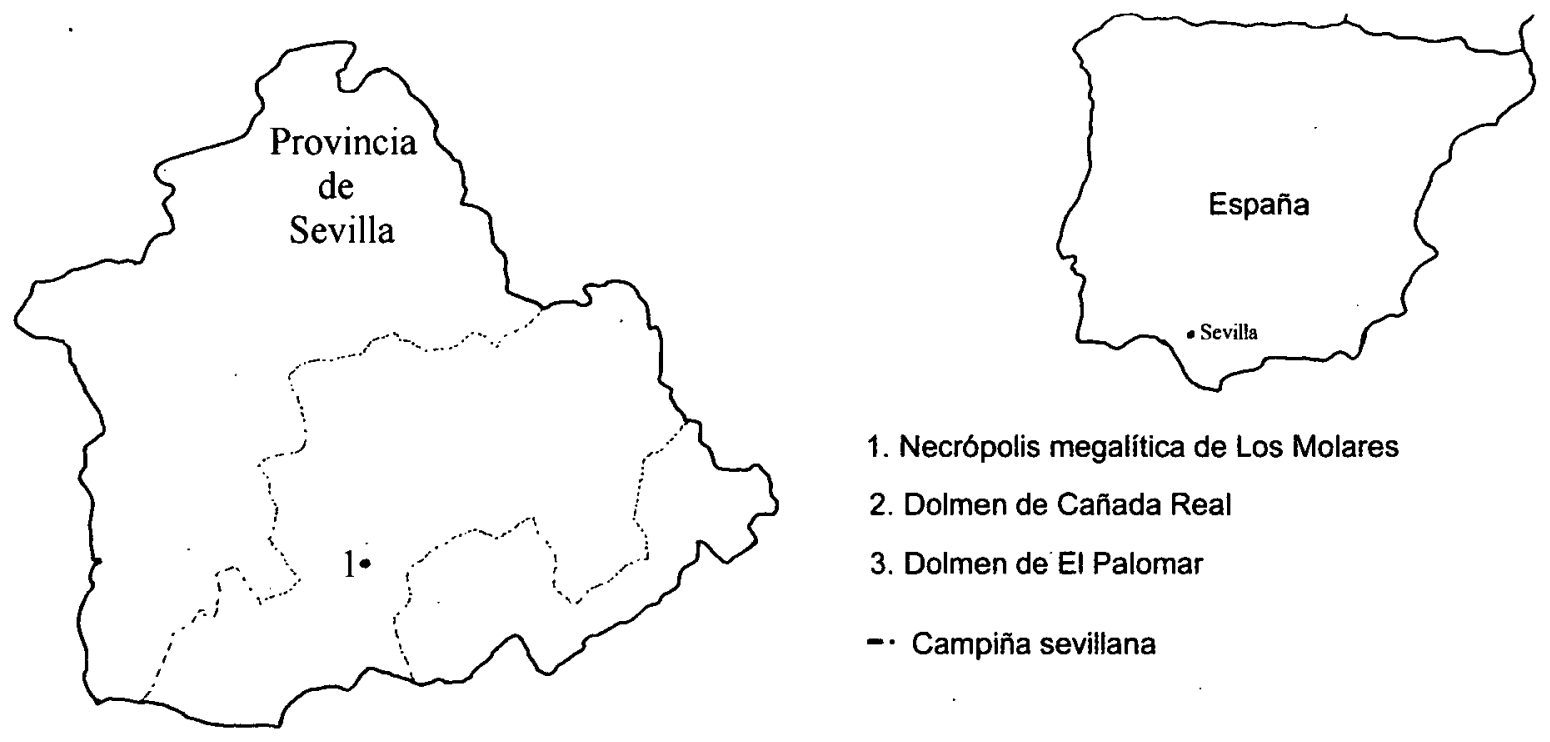

1. Necropolis megalitica de Los Molares

2. Dolmen de Cañada Real

3. Dolmen de El Palomar

- Campiña sevillana

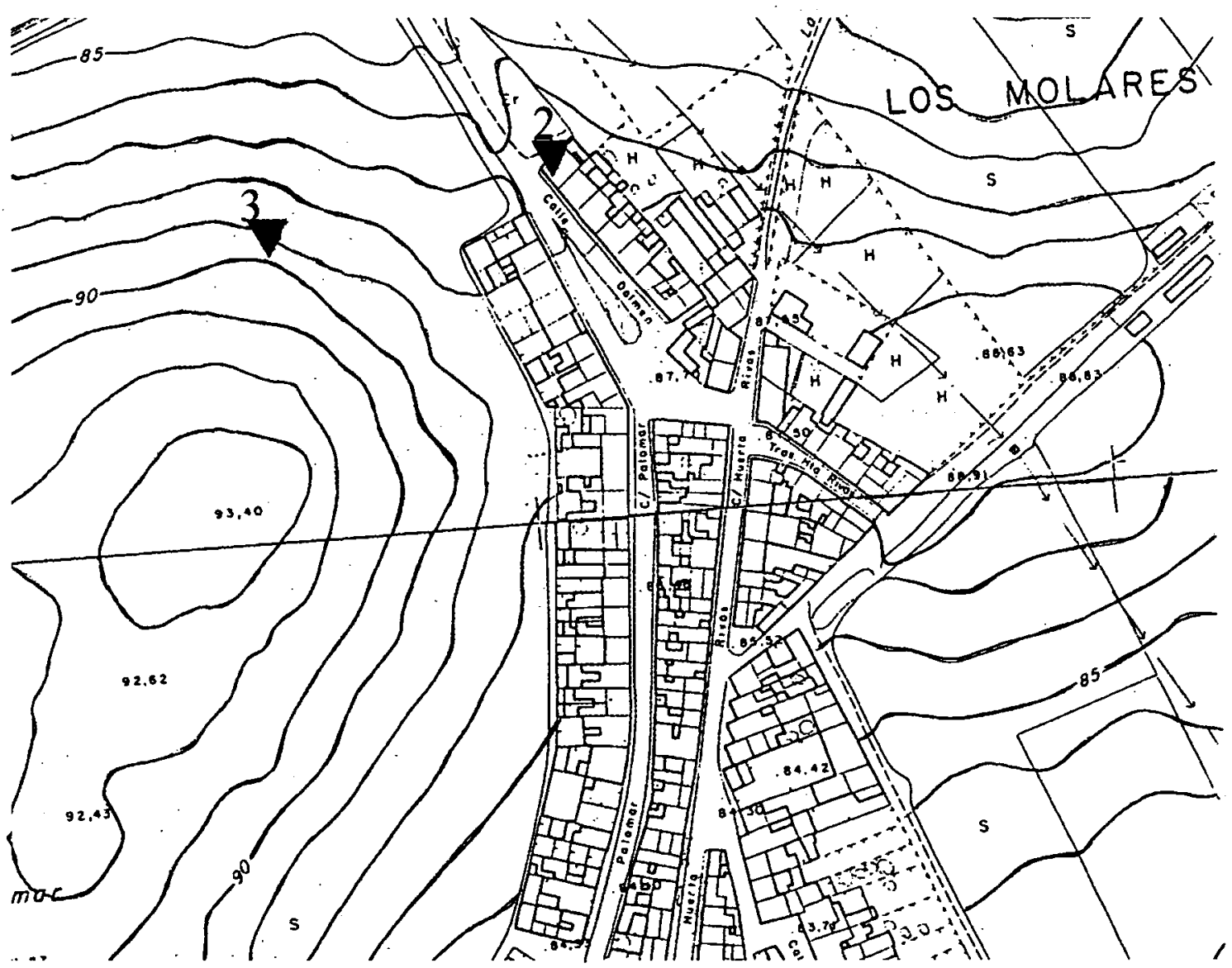

Fig. 1: Situación geográfica de los dólmenes excavados. 

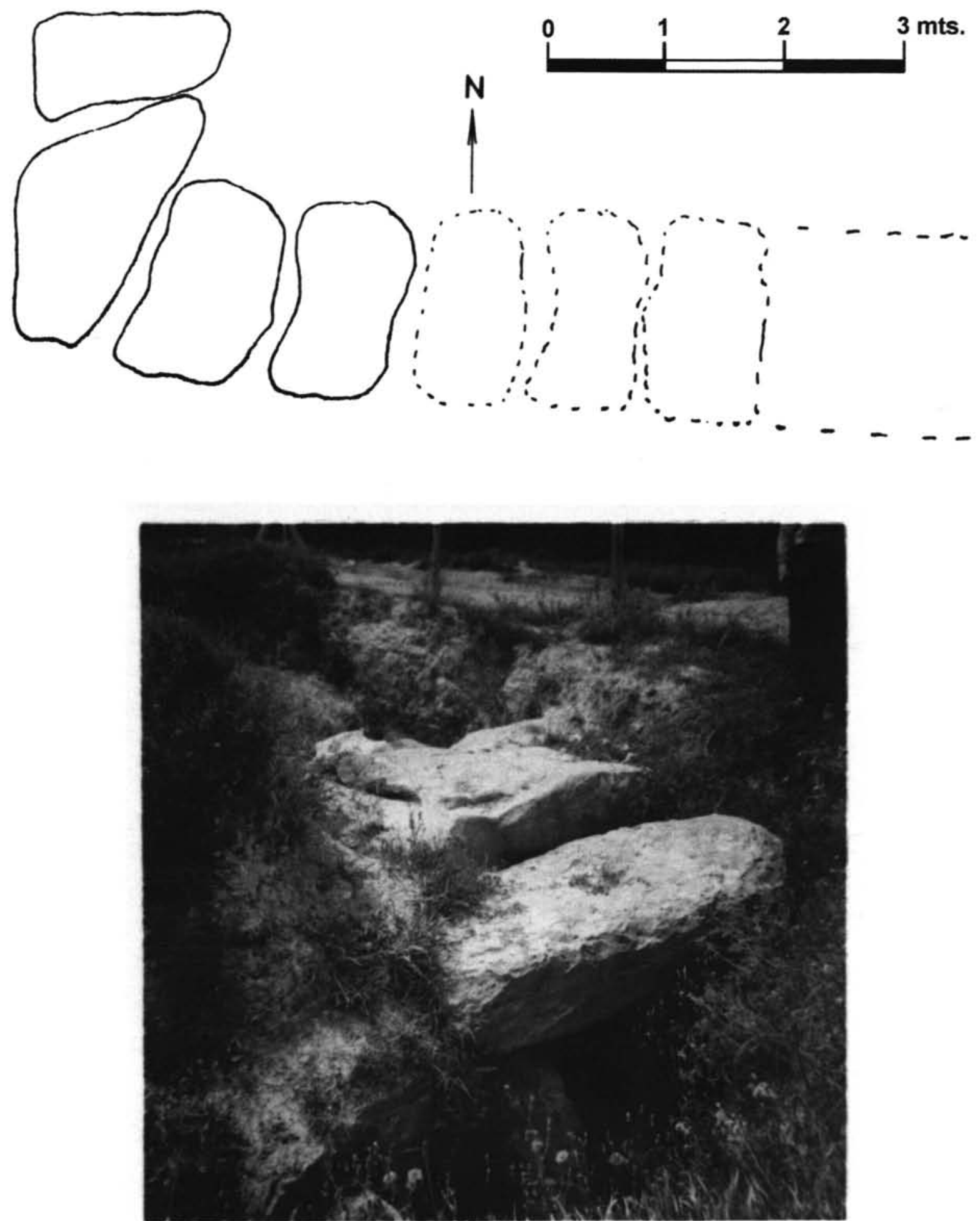

Fig. 2: Dolmen de Cañada Real. Fotografía cedida por D. José Pérez Rincón, vecino de Los Molares 


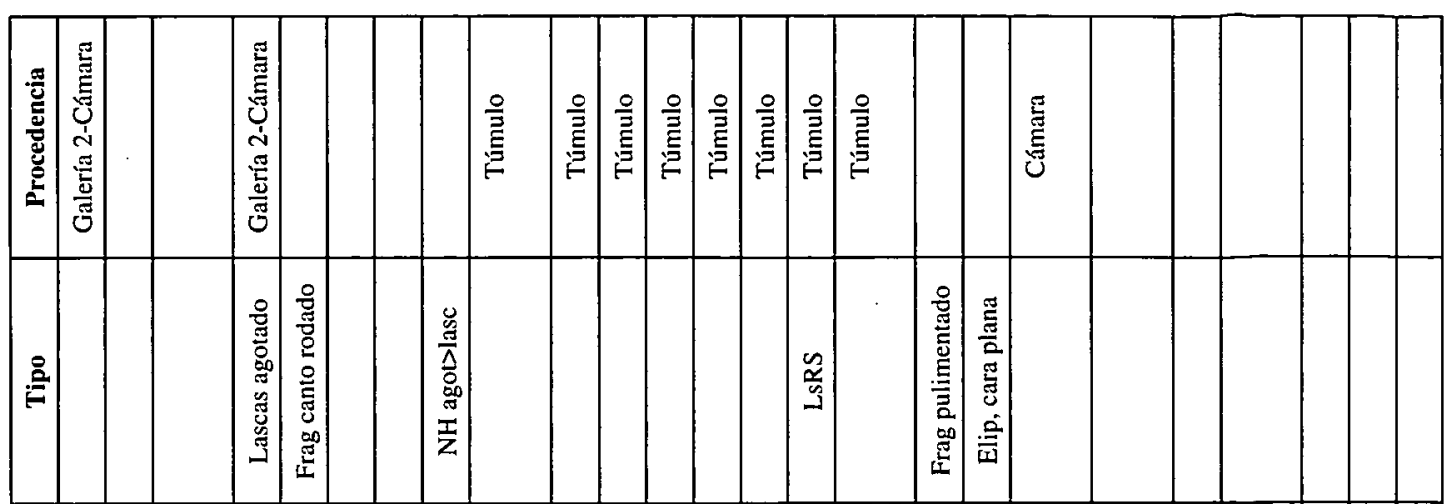

\begin{tabular}{|c|c|c|c|c|c|c|c|c|c|c|c|c|c|c|c|c|c|c|c|c|c|c|c|c|c|}
\hline$\overline{5}$ & & & 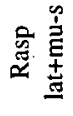 & & & & & & & & & & & & & & & & 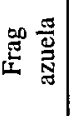 & & & $\begin{array}{l}\frac{5}{5} \\
.5 \\
\frac{5}{4}\end{array}$ & & & \\
\hline$\overline{\underline{x}}$ & & & & & & & & & & & & & & & & & & & & & & & & & \\
\hline$\hat{\underline{z}}$ & & & & & & & & & & & & & & & & & & & & & & & & & \\
\hline $\overrightarrow{\underline{x}}$ & & & 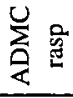 & & & & & & & & & & & & & & & & & & $D$ & & & & \\
\hline$\theta$ & & & $\stackrel{n}{\dot{\Sigma}}$ & & & & & & & & & & & D & & & & & & & $\begin{array}{l}u \\
\vdots \\
\frac{0}{4}\end{array}$ & & & & \\
\hline 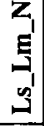 & $\overrightarrow{\mathbf{3}}$ & $I$ & $\overrightarrow{\underline{s}}$ & $z$ & & $\overline{\underline{s}}$ & $\overrightarrow{\underline{3}}$ & 言 & $\sqrt{3}$ & 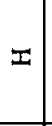 & $I$ & $I$ & $\pm=$ & $I$ & 局 & 番 & & & & 命 & $I$ & Zె & $I$ & $\overrightarrow{3}$ & \pm \\
\hline$\vec{z}$ & $\mathrm{z}$ & $\mathrm{z}$ & $z$ & $\infty$ & $z$ & $\approx$ & $z$ & $\infty$ & $z$ & $z$ & $\mathrm{z}$ & $\mathrm{z}$ & $z=$ & $\mathrm{z}$ & $n$ & $z$ & & & & s & $z$ & $z$ & $z$ & is & $z$ \\
\hline$\underset{\tilde{E}}{\tilde{E}}$ & ه & 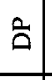 & $a$ & & & & & & & 官 & $\vec{a}$ & $\vec{\Delta}$ & $\circ$ & aे & 2 & & & & 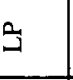 & & $\tilde{\Delta}$ & & 0 & $\vec{\Delta}$ & $a$ \\
\hline $\bar{\Phi}$ & - & $>$ & $>$ & & & - & - & & $\approx$ & $>$ & $>$ & $>$ & $>=$ & $>$ & $>$ & $>$ & & & & - & $>$ & 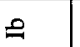 & - & $>$ & $>$ \\
\hline$\infty$ & & & & & & & & & & & & & $r F$ & $F$ & & & & & & & $t$ & & $\Sigma$ & & $\Sigma$ \\
\hline 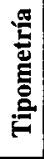 & & & & & & 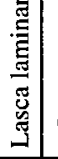 & 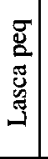 & & 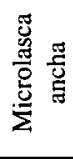 & & & & & & & 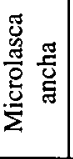 & & & & 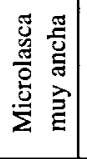 & & 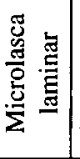 & & & \\
\hline 0 & $\grave{0}$ & $\ddot{0}$ & $\cong$ & $\cong$ & 1 & \begin{tabular}{l|}
$\infty$ \\
0 \\
0
\end{tabular} & $\because$ & 1 & tro & 1 & 1 & $\begin{array}{l}0 \\
0 \\
0\end{array}$ & $\therefore$ & $\begin{array}{ll} \\
0 \\
0\end{array}$ & $\Leftrightarrow$ & m & 1 & $\cong 7$ & $\exists$ & $\hat{o}$ & 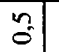 & $\dot{\Delta}$ & $\stackrel{m}{0}$ & 1 & 2 \\
\hline$\approx$ & $\begin{array}{l}m \\
\mathrm{i}\end{array}$ & $\exists$ & $\frac{4}{4}$ & $\begin{array}{l}1 \\
\mathfrak{N}\end{array}$ & 1 & $\begin{array}{l}\infty \\
\text { i }\end{array}$ & î & 1 & $\underline{-}$ & 1 & 1 & 1 & $m$ & 2 & $\overrightarrow{v_{1}}$ & \pm & 1 & 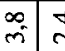 & $\stackrel{\vec{i}}{\mathrm{i}}$ & $\stackrel{\vec{N}}{\mathrm{~N}}$ & \pm & $\cong$ & $=$ & 1 & $\because$ \\
\hline- & $\stackrel{\infty}{-1}$ & $\stackrel{\infty}{\sim}$ & 1 & $\hat{i}$ & 1 & m & î & 1 & \pm & 1 & 1 & 1 & 1 & 11 & 1 & $\Xi$ & 1 & \begin{tabular}{c|l}
$\infty$ \\
$\sigma$ \\
$\sigma$
\end{tabular} & $\begin{array}{l}n \\
m \\
m\end{array}$ & $=$ & 1 & ב্ & 1 & 1 & 1 \\
\hline $\begin{array}{c}5 \\
5 \\
3 \\
3\end{array}$ & 3 & $\Xi$ & 3 & $\bar{z}$ & 1 & 3 & 3 & $\bar{z}$ & 3 & $\Xi$ & $\Xi$ & $\underline{\Xi}$ & $\xi$. & $\Xi$ & a. & 3 & 1 & 1 & 1 & 3 & $\Xi$ & 3 & $\Xi$ & 3 & $\Xi$ \\
\hline $\bar{m}$ & $\tilde{z}$ & $\infty$ & is & 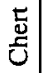 & $\Xi$ & 忽 & 8 & $\infty$ & $\begin{array}{l}\text { E⿱ } \\
\text { Uू }\end{array}$ & 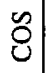 & 8 & $\ddot{8}$ & $\ddot{8}$ & 8 & 3 & 8 & 古 & 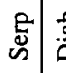 & 号 & 8 & $\infty$ & $\tilde{8}$ & 8 & $\Xi$ & $\tilde{8}$ \\
\hline$\overline{\tilde{x}}$ & 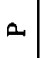 & $\circ$ & $a$ & $a$ & a & $\infty$ & Q & 0 & a & $\sim$ & $a$ & 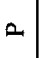 & a & هـ & 2 & ه & 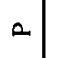 & 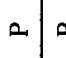 & a & a & $a$ & a & $a$ & 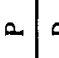 & $a$ \\
\hline $\mathbf{z}$ & 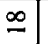 & $\infty$ & i & $m$ & $\nabla$ & $\simeq$ & 9 & $n$ & $\bar{N}$ & $=1$ & 9 & $\approx$ & a: & $\simeq$ & 2 & I & $?$ & $\vec{\infty} \mid-$ & - & $I$ & $N$ & 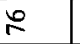 & $\approx$ & 2 & $\approx$ \\
\hline is & 客 & $\overline{\bar{\beth}}$ & $\underset{\tilde{\sigma}}{\tilde{I}}$ & 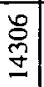 & \begin{tabular}{l|}
$\frac{g}{\sigma}$ \\
$\frac{g}{g}$
\end{tabular} & $\frac{a}{\vec{m}}$ & $\frac{a}{\tilde{g}}$ & $\frac{9}{\vec{g}}$ & $\frac{0}{\tilde{g}}$ & $\begin{array}{l} \\
\stackrel{0}{3}\end{array}$ & \begin{tabular}{l|}
$\frac{0}{3}$ \\
$\frac{\sigma}{\Xi}$
\end{tabular} & \begin{tabular}{l|}
0 \\
$\frac{0}{9}$ \\
\end{tabular} & \begin{tabular}{l|}
0 \\
$\frac{0}{2}$ \\
\end{tabular} & $\frac{0}{\frac{0}{5}}$ & $\frac{e}{2}$ & $\frac{\mathscr{0}}{\underline{\Xi}}$ & 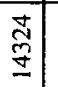 & 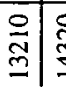 & 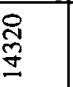 & $\frac{\sigma}{\vec{\sigma}}$ & $\frac{\sigma}{\vec{g}}$ & $\frac{a}{\vec{g}}$ & \begin{tabular}{l|l}
$\frac{\sigma}{\vec{v}}$ \\
\end{tabular} & $\frac{\Omega}{\vec{g}}$ & $\frac{a}{\vec{g}}$ \\
\hline \# & - & $N$ & $\mathrm{~m}$ & $\sigma$ & in & 0 & $\pi$ & $\infty$ & $a$ & बे & $=$ & $\nexists$ & $9 ;$ & $\exists$ & 9 & $\Xi$ & $\approx$ & $\stackrel{\infty}{\infty}$ & 2 & ते & $\vec{\pi}$ & $\boldsymbol{N}$ & $\pi$ & $\mathbb{Z}$ & 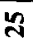 \\
\hline
\end{tabular}


En 1980 se descubrió el Dolmen de El Palomar (Fig. 7). Ocurrió fortuitamente, al arrancar unos olivos, y fue excavado por miembros del Museo Arqueológico de Sevilla. La dirección de esta excavación arqueológica de urgencia corrió a cargo de Diego Oliva Alonso y Manuel Ma Ruiz Delgado (Arqueología 81 1982: 122). Toda la documentación obtenida ha pasado a formar parte de los proyectos antes mencionados, y está siendo investigada junto con la de Cañada Real. De ellos han salido ya varias publicaciones (Cabrero et alii 1995: 69-79; Cabrero et alii 1996: 191-200).

\section{DOLMEN DE CAÑADA REAL (LOS MOLARES, SEVILLA)}

\section{A.- Inventario General}

\section{INDUSTRIA LÍTICA TALLADA}

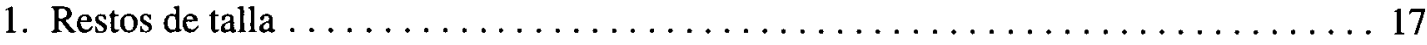

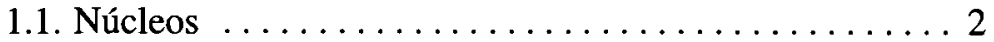

1.1.1. Globulosos $\ldots \ldots \ldots \ldots \ldots \ldots \ldots$

1.1.2. Diversos $\ldots \ldots \ldots \ldots \ldots \ldots \ldots \ldots$

1.2. Lascas y láminas $\ldots \ldots \ldots \ldots \ldots \ldots \ldots \ldots \ldots \ldots$

1.2.1. Lascas de semidescortezado ....... 1

1.2.2. Lascas Internas ............. 5

1.2.3. Hojas .................. 7

1.2.4. Lascas del desbaste de núcleos ..... 1

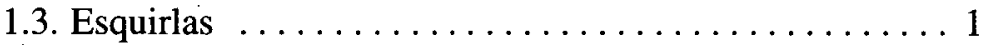

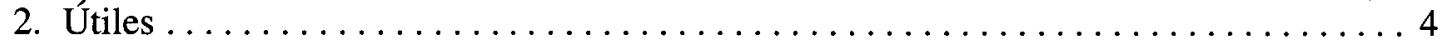

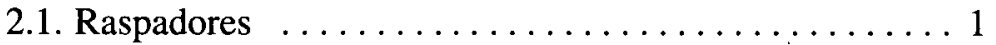

2.2. Lascas y láminas retocadas $\ldots \ldots \ldots \ldots \ldots \ldots \ldots \ldots$

2.2.1. Retoque simple .............

2.2.2. Retoque abrupto $\ldots \ldots \ldots \ldots \ldots 1$

2.2.3. Retoque de uso $\ldots \ldots \ldots \ldots \ldots \ldots 1$

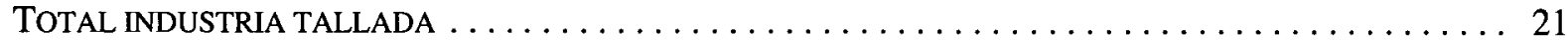

INDUSTRIA LÍTICA PULIMENTADA

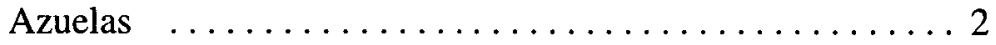

Fragmento no identificable $\ldots \ldots \ldots \ldots \ldots \ldots \ldots \ldots$

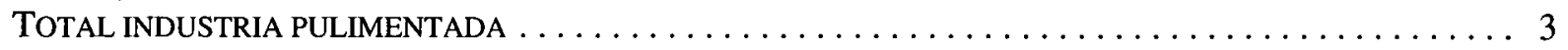

OTROS

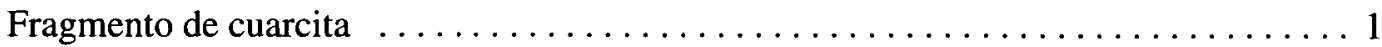

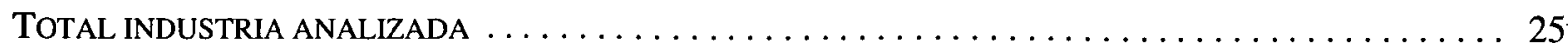




\section{B.- Estudio descriptivo}

\section{RESTOS DE TALLA}

1.1. NúCLEOS. Los núcleos representan el $9,5 \%$ del total de la industria lítica tallada. Sus dos ejemplares han sido clasificados como:

1.1.1. Núcleo globuloso (NG): Esta pieza se caracteriza por sus pequeñas dimensiones (longitud máxima $<3 \mathrm{~cm}$ ), lo que incide en el alto grado de aprovechamiento de la materia prima antes de su abandono. Realizado sobre chert, se caracteriza por una técnica de talla inmersa dentro de una tendencia giratoria de la pieza a la hora del desbaste, lo que mediante una serie de apoyos sucesivos ha permitido la extracción principalmente de lascas internas.

1.1.2. Núcleo diverso (NDiv): Una pieza realizada sobre sílex que presenta una morfología actual que dificulta su adscripción tecnológica; sin embargo, parece tratarse de un núcleo para hojas de talla a presión y tendencia vertical, que ha sido agotado mediante una técnica giratoria de talla para la obtención de lascas. Este aprovechamiento del material incide en la idea ya mencionada de la explotación profunda de la materia prima antes de su definitivo abandono.

\subsection{LASCAS Y LÁMINAS}

1.2.1. Lascas de descortezado(LsD): Procedente de los momentos iniciales del desbaste, de la talla externa o descorticado del material a trabajar, su presencia es frecuente en los lugares primarios de talla, como indicadora de una determinada actividad de trabajo. Sin embargo, en este caso su significado cualitativo no permite generalizaciones, al tratarse de una sola pieza de escasas dimensiones, de semidescortezado procedente de una caliza oolítica silicificada.

1.2.2. Lascas internas (LsI): Son cinco ejemplares con una tipometría que presenta una media de longitud de 1,9 , anchura 2,1 y espesor 0,6 . Se han realizado dos de ellas sobre calizas oolíticas silicificadas, una sobre chert -al igual que el núcleo globuloso para lascas, del que pudiera proceder-y las otras sobre una cuarcita y una cuarzarenita, conservando ambas restos de la corteza de la roca madre. Es de destacar la gran variedad de materiales que se han tallado y de los que se han desprendido estas lascas internas, que no parecen tener un carácter intencional, sino que corresponden a los residuos de la talla de unos núcleos de materiales variados que no se han encontrado.

1.2.3. Hojas (H): Presentamos siete hojas de talla a presión sin retocar. La fabricación de estas piezas responde a una cadena operativa muy precisa y elaborada, que se basa en la cuidadosa preparación de un núcleo con carácter acanalado que, mediante una talla vertical, permite la obtención de estas piezas de filos rectilíneos y paralelos. No se han encontrado entre el material analizado ninguno de estos núcleos para hojas, aunque ya hemos mencionado la posible reutilización del núcleo diverso. Todas presentan un grado de fracturación elevado por lo que, al estar incompletas, su tipometría no puede precisarse. Entre las no fracturadas lateralmente las anchuras oscilan entre 13 y $15 \mathrm{~mm}$, lo que corresponde a hojas estrechas. Tan sólo una de ellas alcanza los $33 \mathrm{~mm}$. Las secciones, en los casos reconocibles son en su mayor parte triangulares (tres piezas), aunque en consonancia con las trapezoidales (dos ejemplares). Tan sólo una de ellas ha sido fabricada sobre sílex; las demás utilizan la caliza oolítica silicificada como soporte, debido a la gran calidad de este material, que permite una fractura limpia y cortante.

1.2.4. Lasca del desbaste de núcleo (LsDN): Completando la visión tecnológica de la talla presentamos esta lasca que procede del desbaste de una arista o flanco de núcleo para despejar un nuevo plano de golpeo. Se trata de una lasca procedente de un núcleo de caliza oolítica silicificada que pudiera haberse desprendido de un núcleo para hojas de talla a presión en cualquiera de sus primeros pasos configuradores de la talla laminar. 
2. ÚTILES. Se trata de un conjunto de cuatro piezas retocadas secundariamente para la conformación de los propiamente definibles como productos de talla y que obedecen a un criterio tipológico que se puede relacionar con una consideración funcional, sin la cual no tendrían sentido. Este último aspecto, el de la funcionalidad, presenta grandes controversias, debido a la dificultad para precisar. Para ello se hacen imprescindibles los estudios funcionales y traceológicos que liberen a las tipologías de las sujeciones meramente morfo-funcionales basadas en la utilización del "sentido común" o el parecido con formas actuales de determinados útiles ${ }^{5}$.

2.1. RASPADOR(R): Se trata de una pieza realizada sobre una lasca interna de sílex. Presenta fractura proximal, por lo que su talón se encuentra abatido. Realmente se trata de un útil compuesto, ya que en el lateral derecho se ha definido una muesca simple de tipo clactoniense; en el lateral izquierdo se sitúa el frente del raspador, definido mediante retoques abruptos, directos, marginales y continuos, que definen un raspador corto lateral. La presencia de la muesca definiría quizás la posibilidad de un retoque de acomodación para facilitar la utilización de la pieza o su posible enmangamiento.

2:2 Lascas y láminas retocadas. La presencia de retoques en estas piezas hace que deban ser incluidas dentro de las modificadas por una acción tipológica; sin embargo, la falta de precisión de sus retoques impide su inclusión dentro de las listas tipológicas. De tal manera hemos definido:

2.2.1. Lasca de semidescortezado con retoque simple (LsRS), directo y marginal en su lateral derecho.

2.2.2. Lámina, hoja de talla a presión, con retoques abruptos (LmRA), inversos y profundos en su lateral derecho. En el lateral izquierdo presenta algunas huellas de uso, lo que podría indicar que éste fuera el lado útil o filo activo, mientras que los retoques abruptos servirían para abatir el filo en función de una posible utilización o enmangamiento de la pieza.

2.2.3. Lámina con retoque de uso ( $\mathrm{LmRU})$ en su lateral derecho sobre una hoja de talla a presión que presenta fractura distal y proximal.

\section{C.- Inventarios porcentuales}

INVENTARIO PORCENTUAL SOBRE EL TOTAL DE LA INDUSTRIA

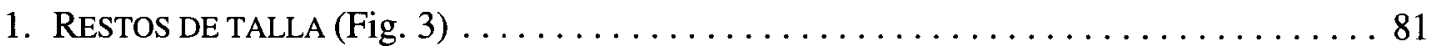

1.1. Núcleos ....................... 9,5

1.1.1 Globulosos $\ldots \ldots \ldots \ldots \ldots \ldots 4,8$

1.1.2. Diversos $\ldots \ldots \ldots \ldots \ldots \ldots .4,8$

1.2. Lascas y láminas $\ldots \ldots \ldots \ldots \ldots \ldots \ldots \ldots 6,7$

1.2.1. Lascas de semidescortezado .... 4,8

1.2.2. Lascas internas $\ldots \ldots \ldots \ldots \ldots 23,8$

1.2.3. Hojas ............... 33,3

1.2.4. Lascas del desbaste de núcleos ... 4,8

1.3. Esquirlas $\ldots \ldots \ldots \ldots \ldots \ldots \ldots \ldots \ldots \ldots \ldots, 8$

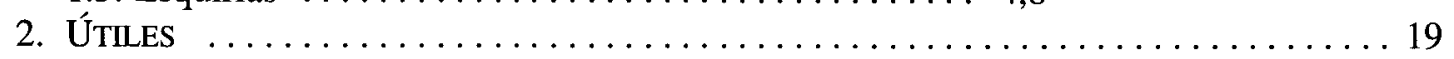

2.1. Raspadores ............... 4,8

2.2. Lascas y láminas retocadas $\ldots \ldots \ldots \ldots \ldots \ldots \ldots \ldots \ldots \ldots \ldots, 14,3$

2.2.1. Retoque simple ......... 4,8

2.2.2. Retoque abrupto $\ldots \ldots \ldots \ldots \ldots 4,8$

2.2.3. Retoque de uso $\ldots \ldots \ldots \ldots \ldots .4,8$

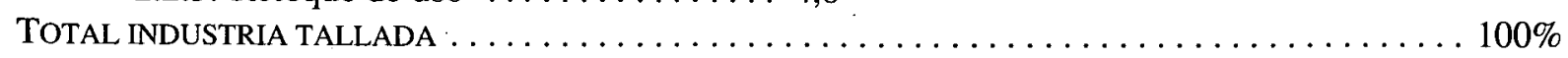

5. Están en vías de realización. 
Azuelas 66,7

Fragmento no identificable

Fragmento de cuarcita $100 \%$

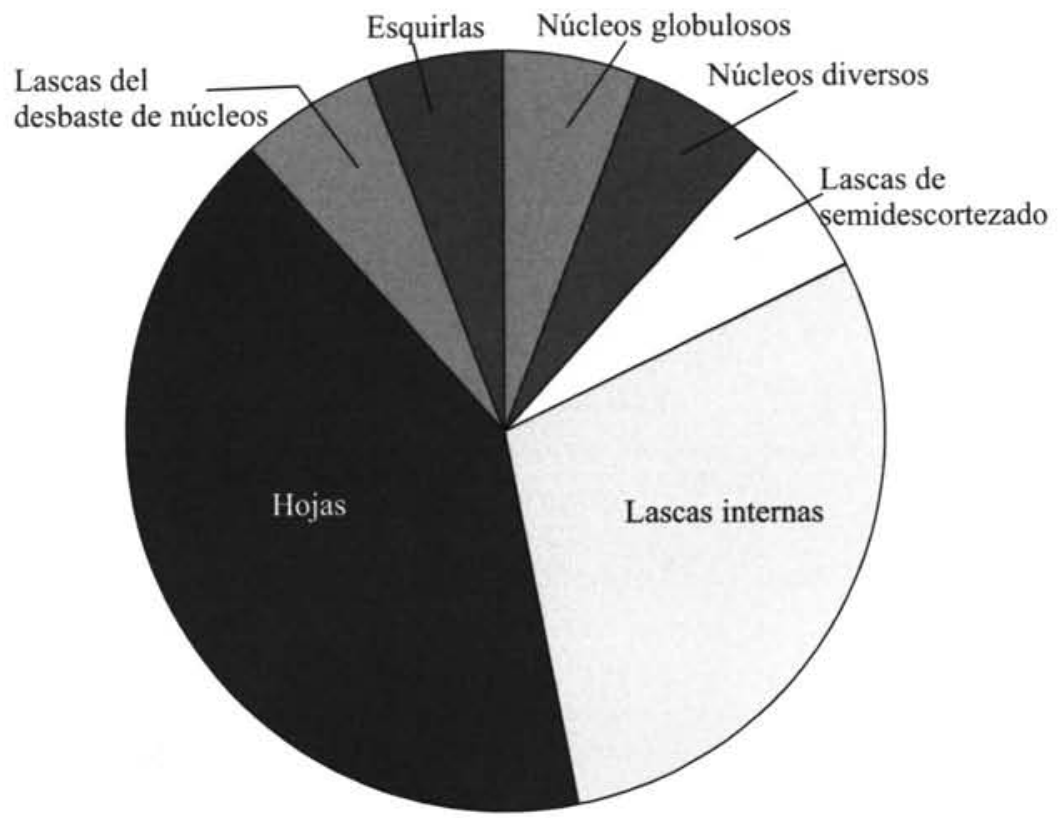

Fig. 3. Restos de talla

\section{INVENTARIO PORCENTUAL POR GRUPOS}

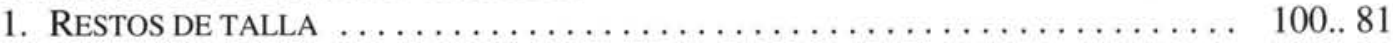

1.1. Núcleos

100.. 11,8

1.1.1. Globulosos ............. 50

1.1.2. Diversos .............. 50

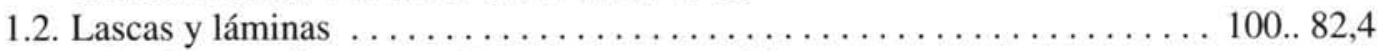

1.2.1. De semidescortezado ........ 7,1

1.2.2. Internas ................ 35,7

1.2.3. Hojas ................. 50

1.2.4. Del desbaste de núcleos $\ldots \ldots \ldots 7,1$

1.3. Esquirlas ....................... 5,9

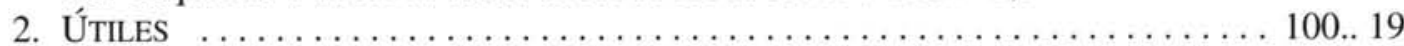

2.1. Raspadores ................ 25

2.2. Lascas y láminas retocadas ............ 75

2.2.1. Retoque simple .............25

2.2.2. Retoque abrupto $\ldots \ldots \ldots \ldots .25$

2.2.3. Retoque de uso ..............25

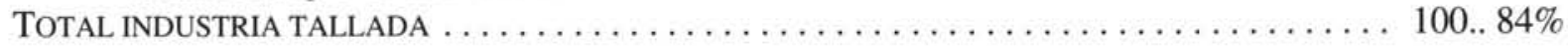


Azuelas . . . . . . . . . . . . . . . . . 66,7

Fragmento no identificable . . . . . . . . . . 33,3

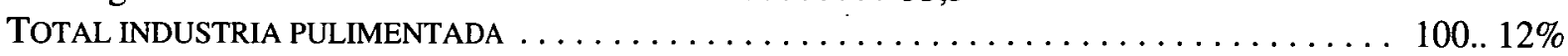

Fragmento de cuarcita $\ldots \ldots \ldots \ldots \ldots \ldots \ldots, 4 \%$

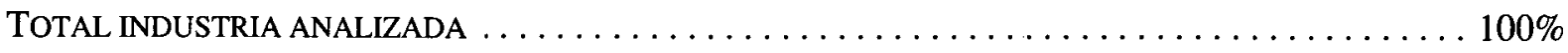

\section{D.- Materiales}

INDUSTRIA LÍTICA TALLADA

Caliza Oolítica Silicificada . . . . . . . . . 13 .. 61,9\%

Sílex . . . . . . . . . . . . . . . . . . . . 4 .. 19,0\%

Chert $\ldots \ldots \ldots \ldots \ldots \ldots \ldots \ldots \ldots \ldots 2$.. $9,5 \%$

Cuarzarenita . . . . . . . . . . . . . . . . $4,8 \%$

Cuarcita ...................... 4,8\%

TOTAL ......................... $21 . .100 \%$

\section{INDUSTRIA LÍTICA PULIMENTADA}

Diabasa ....................... 2.. 50\%

Cuarcita ........................ $1 . .25 \%$

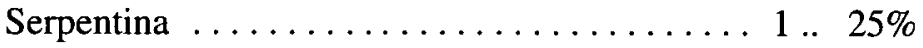

TOTAL ........................ 4 . 100\%

Se trata de materiales de buena calidad, tanto para la talla como para el pulimento (Fig. 4).

\section{E.- Rodamiento}

El 100\% de las piezas no presentan ningún grado de rodamiento, es decir, presentan sus aristas frescas y distinguibles sin haber sufrido alteraciones postdeposicionales de carácter mecánico. En ello incide el grado de protección de la intemperie de que debieron disfrutar, al tratarse de un conjunto cerrado. De la misma manera podemos afirmar que cuando se depositaron dentro del dolmen eran piezas frescas que debieron haber sido talladas sin haber sido posteriormente expuestas al rodamiento.

\section{F.- Cómputo general de restos de talla y útiles}

Del conjunto analizado, el $81 \%$ corresponde a restos de talla, mientras que tan sólo un $19 \%$ se trata de útiles. Dentro de los restos de talla, el $82,4 \%$ se constituye por lascas y láminas sin retocar, siendo, con diferencia, el grupo mejor representado. Los demás restos de talla corresponden a núcleos $(11,8 \%)$ y esquirlas $(5,9 \%)$. El porcentaje de núcleos es bastante reducido en comparación con el correspondiente a lascas y láminas; sin embargo, esto incide en la idea de que la talla se habría realizado previamente a la deposición de las piezas en el interior del dolmen, por lo que sus negativos o soportes nucleares habrían sido abandonados una vez finalizada la talla. Es evidente la desproporción entre restos de talla y útiles. La abrumadora mayoría de estas piezas pudiera obedecer a criterios que lamentablemente se nos escapan, quizá por inexactitudes 


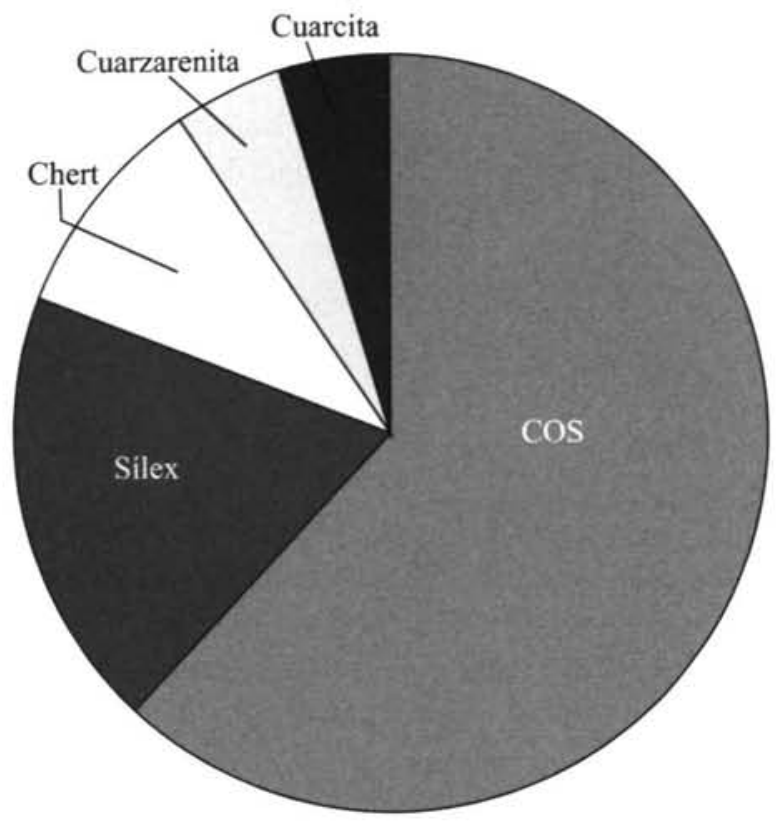

Fig. 4a. Materiales industria tallada

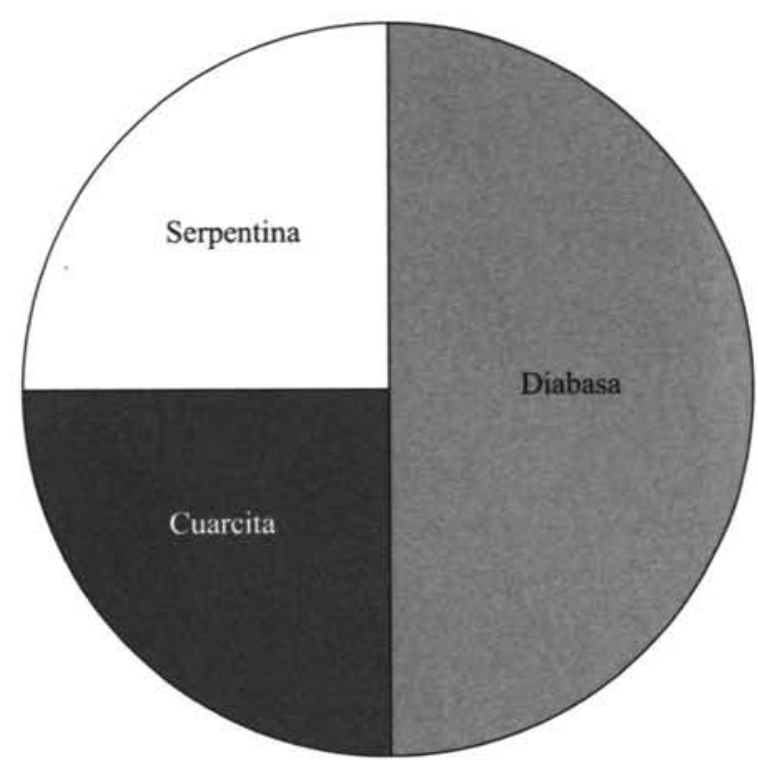

Fig. 4b. Materiales industria pulimentada

en la recogida de materiales durante la excavación, y que no podemos precisar, debido a las pequeñas dimensiones del conjunto que analizamos (Fig. 5).

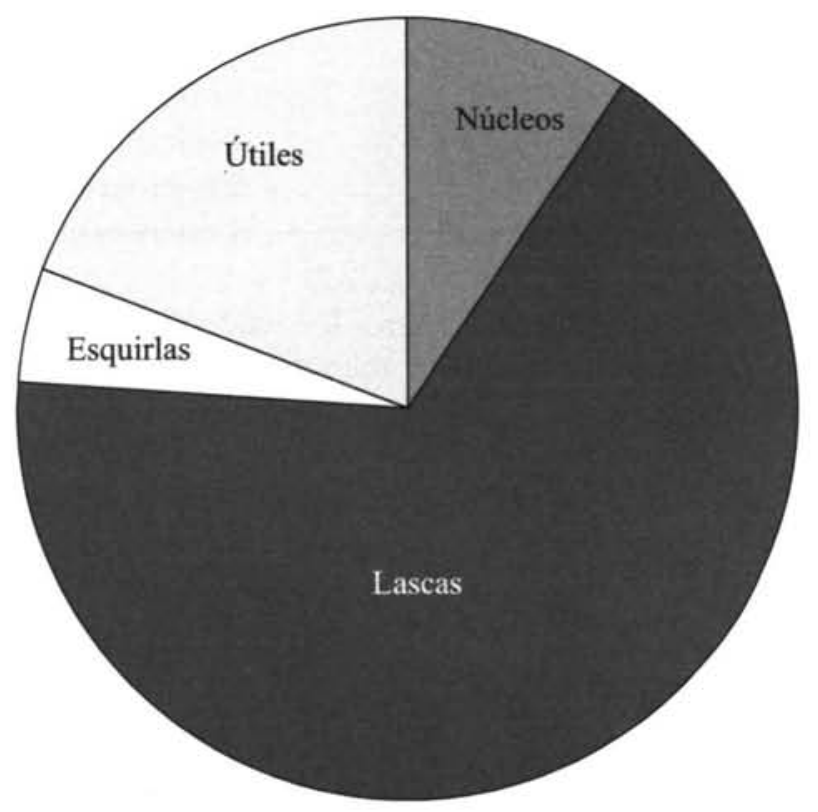

Fig. 5. Restos de talla y útiles 


\section{G.- Talones}

A través del estudio de los restos del plano de golpeo inicial del que proceden las piezas lascadas, podemos aproximarnos a los modos y técnicas del trabajo de la talla, y a la definición de la morfología de unos núcleos que no se han conservado.

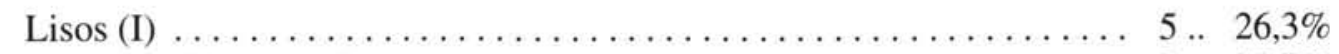

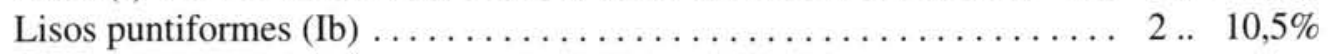

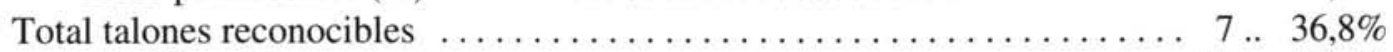

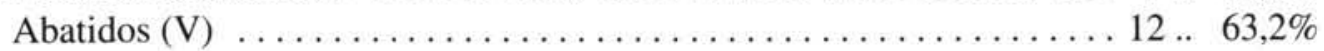

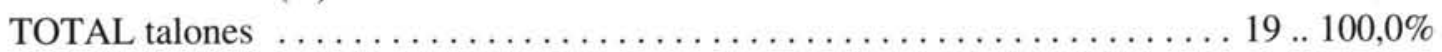

Como ya se ha comentado en el análisis de los materiales, gran parte de ellos presentan fracturas proximales, lo que se manifiesta en la presencia elevada de talones abatidos, que se corresponde en gran medida con los de las hojas. A continuación se sitúan los talones lisos, que corresponden a planos de golpeo preparados en los núcleos, y los lisos puntiformes, definidos en una lasca interna y en la de extracción de una arista de núcleo (Fig. 6).

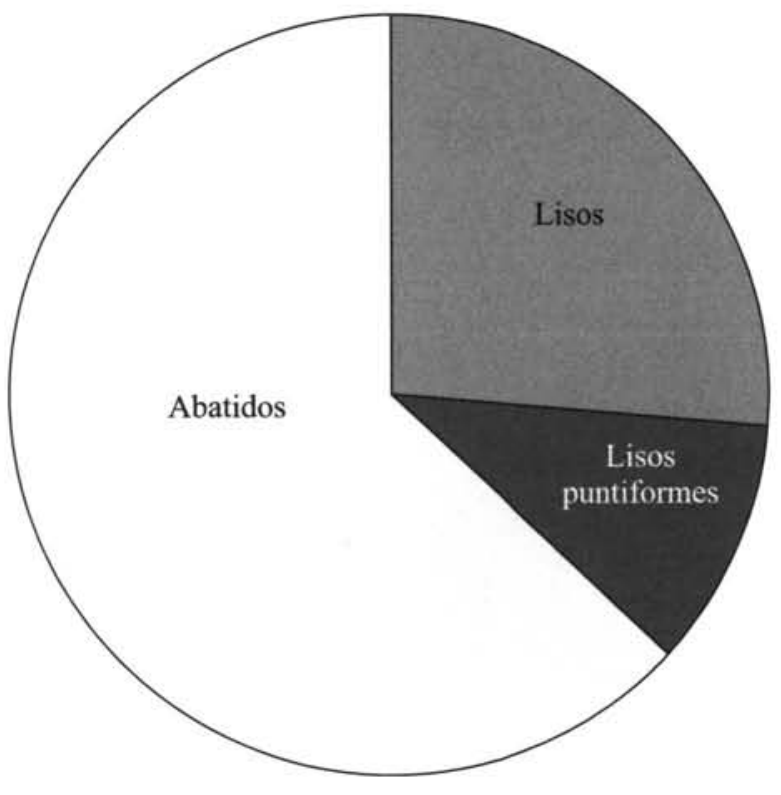

Fig. 6. Talones restos de talla

\section{H.- Tipometría}

Tan sólo pueden ser sometidas al análisis tipométrico de Bagolini (Bagolini 1968) un total de seis piezas, por ser éstas las únicas que no presentan ninguna fractura.

Tipos de pequeño tamaño:

- 1 lasca laminar

-1 lasca pequeña

Tipos de muy pequeño tamaño:

-1 microlasca laminar

-2 microlascas anchas

-1 microlasca muy ancha

De todo ello podemos destacar la tendencia al microlitismo de estas piezas, con la excepción de una lasca laminar que se puede incluir dentro de un conjunto tipométrico mayor. Debemos, no obstante, mantener ciertos recelos ante estos datos, dado su peso poco representativo dentro de la totalidad de las piezas descritas, debido a la presencia tan importante de piezas fracturadas (ver apartado J.).

Del estudio de la tipometría de las hojas de talla a presión podemos extraer una serie de datos, teniendo en cuenta que sólo 6 piezas pueden ser medidas en su anchura y 7 en su espesor de las 9 existentes:

- Anchura de las hojas: $10-14 \mathrm{~mm} 4$ (66,7\%); 15-19mm 1 (16,7\%); > 20 mm 1 (16,7\%). Si hacemos una aproximación al resto de las hojas, el último grupo debería incrementarse en dos ejemplares más, y quizá otros tantos el primer grupo. Así las cosas, la mayor parte de las hojas podrían ser clasificadas como estrechas. 
-Espesor de las hojas: 0-6 mm 6 (85,7\%); 7-10 mm 1 (14,3\%). El espesor de las hojas es muy pequeño, en lógica consonancia con la escasa entidad de sus tipometrías y de sus anchuras.

\section{I.- Análisis de los útiles por grupos culturales}

Se han descrito cuatro tipos de útiles:

- Un raspador que puede englobarse en los caracterizados como útiles de sustrato procedentes de la tradición paleolítica, y que perviven durante toda la prehistoria con ligeras modificaciones en su morfología.

- Tres lascas y láminas retocadas, que son constantes desde momentos neolíticos en que se desarrolla la talla a presión; lo que deriva en la aparición de los soportes laminares, hojas, con filo rectilíneo útil que puede ser empleado en bruto. Del desarrollo de estas piezas, especialmente de las hojas con huellas de uso, pudieran derivarse tareas de siega a modo de hoces primitivas, que en momentos avanzados de la Edad del Cobre definirán los elementos dentados u hoces propiamente dichas.

\section{J.- Otros datos}

El índice de fracturación de las piezas es muy elevado. Son catorce elementos con fracturas que se distribuyen en:

Distal ........................ 3 .. 21,4\%

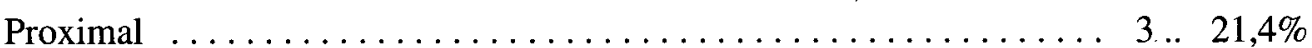

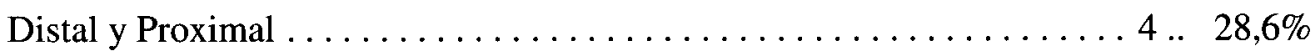

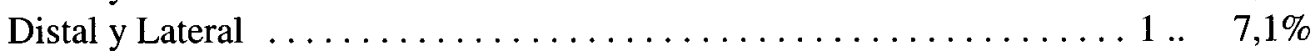

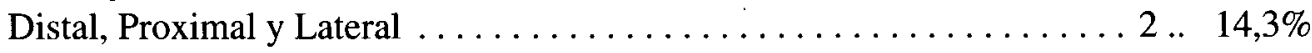

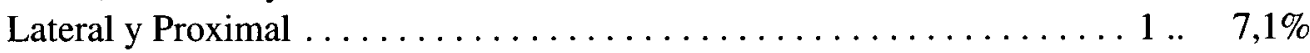

TOTAL ............................ 100,0\%

Respecto a la procedencia de las piezas dentro del túmulo, en la mayor parte de las piezas se desconoce dicho dato:

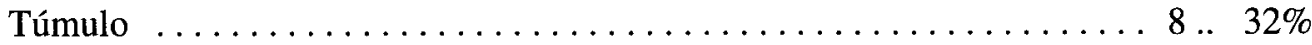

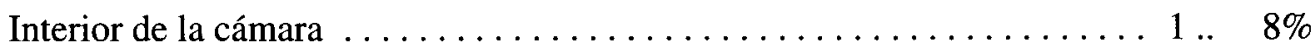

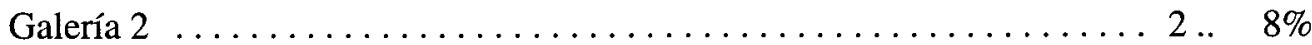

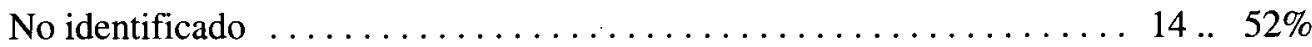

TOTAL ........................................ $100 \%$ 

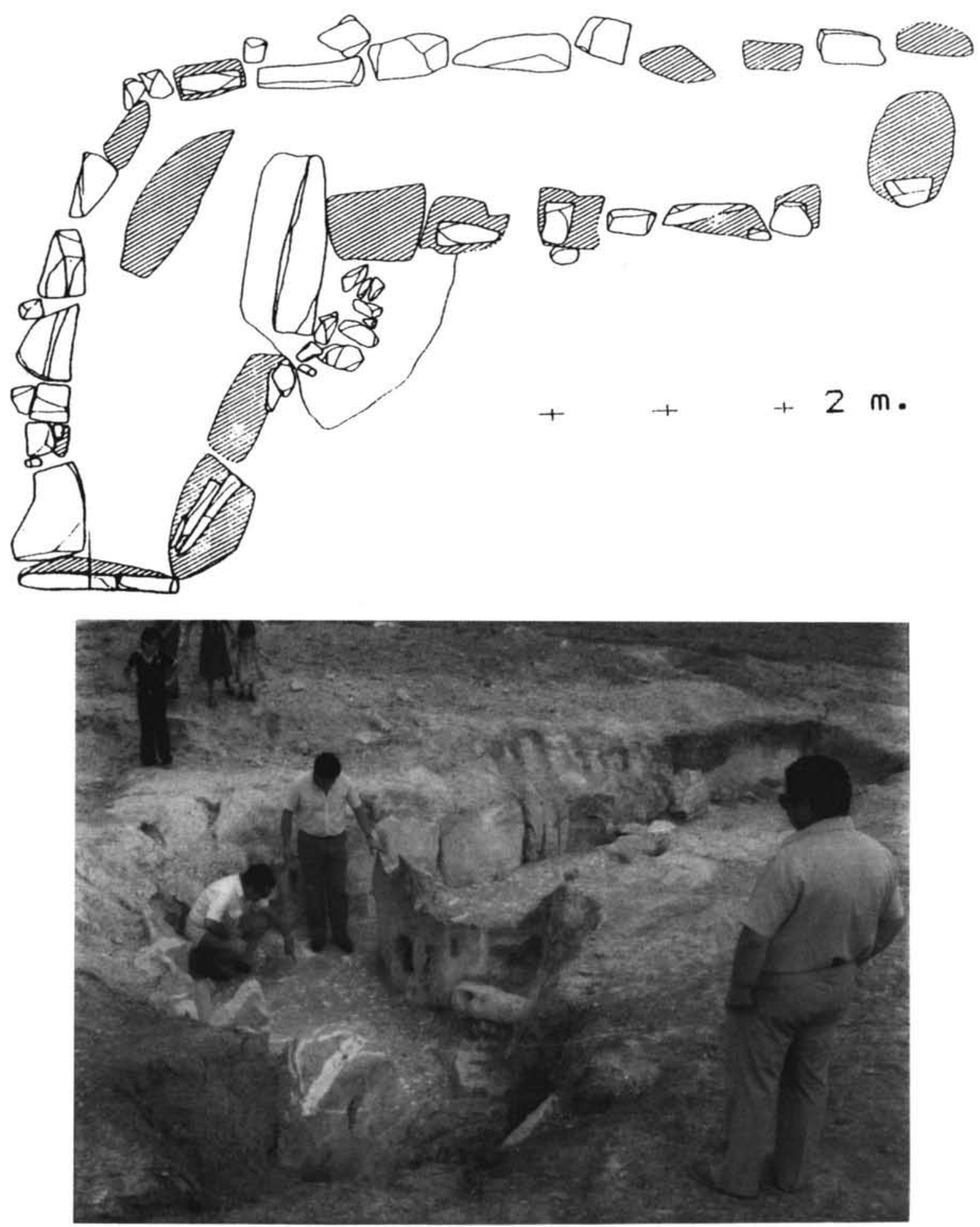

Fig. 7: Dolmen de El Palomar. Fotografía cedida por D. José Pérez Rincón, vecino de Los Molares. 
LA NECRÓPOLIS MEGALÍTICA DE LOS MOLARES: ESTUDIO LÍTICO PRELIMINAR DE LA INDUSTRIA TALLADA... 111

\begin{tabular}{|c|c|c|c|c|c|c|c|c|c|c|c|c|c|c|}
\hline 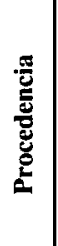 & 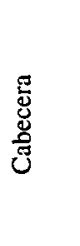 & 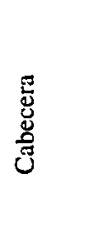 & 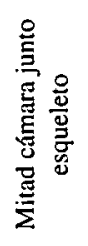 & 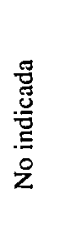 & 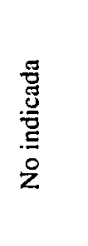 & 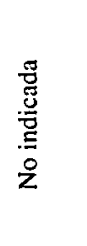 & 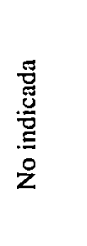 & 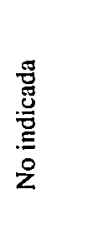 & 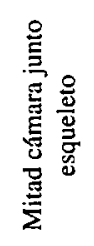 & 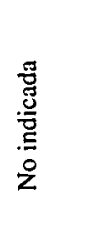 & 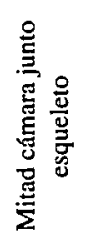 & 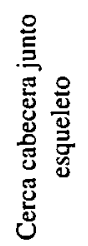 & 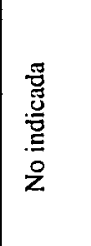 & 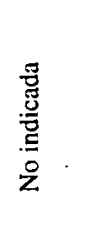 \\
\hline$\stackrel{\stackrel{2}{*}}{=}$ & & & & & & & & & & & & & & \\
\hline$\Xi$ & 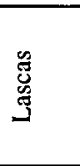 & & & 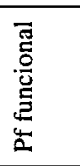 & 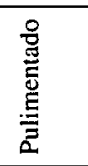 & 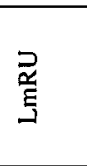 & & $\frac{n}{3}$ & 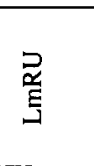 & 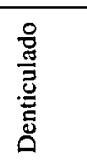 & & & & 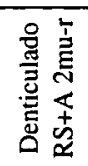 \\
\hline$\hat{\tilde{x}}$ & & & & & & & & & & & & & & $\sum_{4}$ \\
\hline बิ & & & & & & & & & & & & & & \\
\hline$\overline{\mathbf{x}}$ & & & & D & & & & $\sum_{\text {足 }}$ & & & & & & 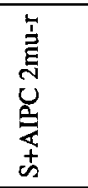 \\
\hline$\stackrel{\theta}{x}$ & & & & & & D & & & $D$ & 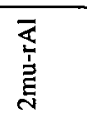 & & & & 宅 \\
\hline 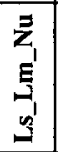 & z & क्ज & $\overline{3}$ & $\sqrt[3]{3}$ & & $I$ & $\overline{3}$ & $\overline{3}$ & $I$ & $\overline{3}$ & 5 & ज्ञ & $\overline{\mathbf{z}}$ & $\overrightarrow{3}$ \\
\hline 5 & $n$ & is & & & & $z$ & is & & & $\approx$ & & $n$ & $n$ & \\
\hline $\bar{E}$ & دـ & a & & & 0 & 芩 & & a & 0 & & & & & \\
\hline बन & & $>$ & $\approx$ & - & & $>$ & - & $>$ & - & 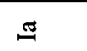 & - & 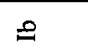 & & $\theta$ \\
\hline$\infty$ & & & & & & $\vdash$ & & & $\Sigma$ & & & & & \\
\hline 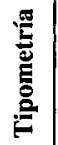 & & & 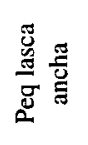 & 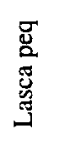 & & & 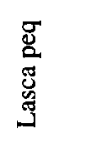 & & & & 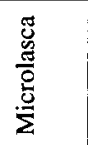 & 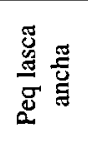 & & 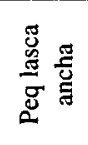 \\
\hline 0 & $\stackrel{-}{0}$ & $\stackrel{0}{\circ}$ & $\hat{\sigma}$ & $\stackrel{\circ}{\circ}$ & $\stackrel{\infty}{=}$ & $\hat{0}$ & $\stackrel{n}{0}$ & $\stackrel{0}{0}$ & $m_{0}^{m}$ & 1 & ț & $\hat{0}$ & $\stackrel{0}{0}$ & $\hat{\theta}$ \\
\hline$\pi$ & 1 & $m$ & $\bar{m}$ & $\tilde{N}$ & $\stackrel{\sim}{*}$ & $\stackrel{n}{i}$ & i & $\overrightarrow{\mathrm{i}}$ & $=$ & 1 & $\cong$ & $\stackrel{n}{s}$ & $\bar{i}$ & $\hat{i}$ \\
\hline- & $\underset{f}{*}$ & 1 & $\vec{m}$ & $\tilde{N}$ & 1 & 1 & $\bar{i}$ & 1 & $\begin{array}{l}\hat{n} \\
\tilde{n}\end{array}$ & 1 & \pm & $\stackrel{+}{i}$ & $\vec{N}$ & $\stackrel{+}{i}$ \\
\hline \begin{tabular}{|l|}
5 \\
5 \\
3 \\
3
\end{tabular} & $z$ & 3 & 3 & 3 & 1 & $\Xi$ & 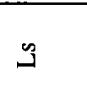 & 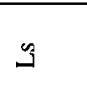 & $\underline{\Xi}$ & 3 & 3 & 3 & $\bar{z}$ & 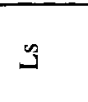 \\
\hline$\sum_{\Sigma}^{\bar{\sigma}}$ & $\infty$ & $\tilde{z}$ & is & 8 & 案 & 8 & $\tilde{8}$ & is & 8 & is & $\tilde{d}$ & n & 8 & 8 \\
\hline $\begin{array}{l}\overline{\mathbf{z}} \\
\mathbb{a}\end{array}$ & $a$ & $a$ & $\therefore$ & $a$ & 2 & 2 & $\Sigma$ & $\Sigma$ & 2 & 2 & 2 & 2 & a & 2 \\
\hline$\frac{\infty}{\dot{n}}$ & 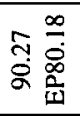 & 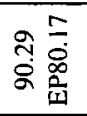 & 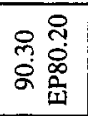 & 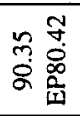 & 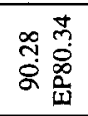 & 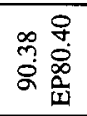 & 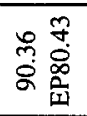 & 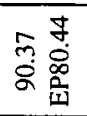 & 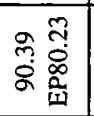 & 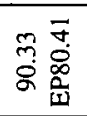 & 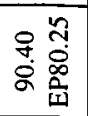 & 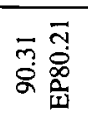 & 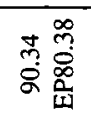 & 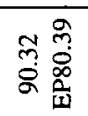 \\
\hline$*$ & - & $N$ & $m$ & $\nabla$ & in & 6 & $r$ & $\infty$ & $a$ & $\stackrel{9}{3}$ & $=$ & $\simeq$ & 2 & $\Xi$ \\
\hline
\end{tabular}




\section{DOLMEN DE EL PALOMAR (LOS MOLARES, SEVILLA)}

\section{A.- Inventario General}

\section{INDUSTRIA LÍTICA TALLADA}

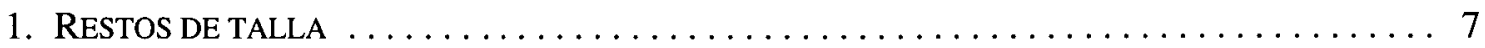

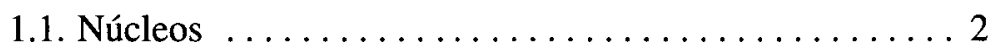

3.1.1. Núcleos discoides $\ldots \ldots \ldots \ldots \ldots 1$

3.1.2. Núcleos para hojas $\ldots \ldots \ldots \ldots \ldots 1$

1.2. Lascas ............................. 5

3.2.1. Lascas de descortezado ......... 2

3.2.2. Lascas internas $\ldots \ldots \ldots \ldots \ldots . \ldots . \ldots$

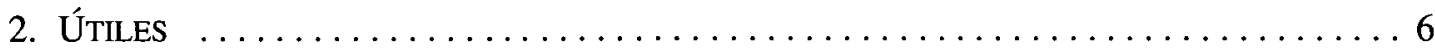

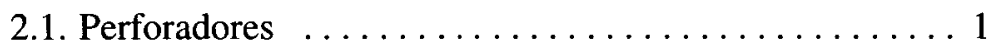

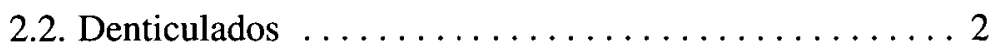

2.3. Lascas/láminas retocadas $\ldots \ldots \ldots \ldots \ldots \ldots \ldots$

2.3.1. Lascas de retoque simple ........

2.3.2. Láminas de retoque de uso ....... 2

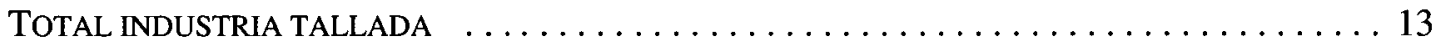

INDUSTRIA LÍTICA PULIMENTADA

Fragmento no identificable ................ 1

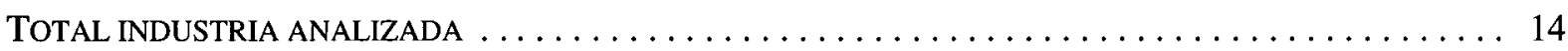

\section{B.- Estudio descriptivo}

\section{RESTOS DE TALLA}

3.1. NúCLEOS. Hemos analizado tan sólo dos ejemplares que corresponden a dos modos distintos de desbaste lítico, a dos diferentes técnicas de trabajo. Su presencia aporta más un valor cualitativo que cuantitativo, dada se escasa representación numérica. Sin embargo, si relativizamos los datos, observamos que estos dos núcleos representan el $15,4 \%$ del total analizado dentro del conjunto tallado del dolmen de El Palomar.

3.1.1. Núcleo discoide (ND): Caracterizado por la presencia de varios planos de golpeo periféricos que definen una extracción centrípeta de lascas principalmente. Conforma un núcleo de aspecto muy agotado y aplanado que ha perdido el abombamiento característico. Tecnológicamente, y dadas las características del conjunto, puede proceder del reaprovechamiento de otro núcleo ya agotado. Representa el 7,7\% dentro del porcentaje general de la industria tallada.

3.1.2. Núcleo para hojas $(\mathrm{NH})$ : Las líneas de extracción que actúan de guía en esta pieza definen un modelo de talla subparalela de tendencia laminar, efectuada posiblemente mediante talla a presión. Sus reducidas dimensiones $(2,1 / 2,1 / 1,6)$ delimitan la obtención de pequeñas hojas estrechas, y confirman el carácter agotado de dicho núcleo.

3.2. LASCAS. Pasamos a la descripción de los restos de talla procedentes de los núcleos, siguiendo un criterio cronológico de talla. Dentro de esta secuencia o proceso inscrito dentro de un tiempo determinado contemplamos la presencia de: 
3.2.1. Lascas de descortezado(LsD): Tan sólo dos ejemplares, pero considerando que partimos de un conjunto de catorce piezas, su porcentaje relativo con respecto al total analizado se dispara hacia el $15,4 \%$. Esto dota a este conjunto de una nueva significación dentro de la cadena operativa de trabajo, tanto como parte obligada del desbaste como dentro de la secuencia de significado que su abandono deposicional aporta dentro del conjunto de un enterramiento. Podemos precisar que estas dos piezas aparecieron en la cabecera de la cámara, junto al esqueleto. Lamentablemente, al disponer de un material tan escaso no podemos permitimos una aproximación a su significado casual o intencionado, dado la mínima representatividad que poseen.

3.2.2. Lascas internas (LsI): Es el conjunto mejor representado, aunque sólo contamos con tres ejemplares $(23,1 \%$ del total de la industria tallada). Dos de ellas presentan una tipometría similar, con una media de 2,25/2,15/0,7 en la proporción $1 /$ a/e. La otra lasca interna la incluimos dentro de un apartado que se conoce como lascas internas de retoque, y que se basa únicamente en criterios tipométricos, pero que hacen referencia a la tecnología de la que proceden, incluyéndolas dentro de un momento secundario de la talla, que afecta al retoque para la conformación de los útiles.

4. ÚTILES. Se definen como los auténticos productos de la talla, como el objeto que se ha pretendido obtener para la culminación de la tarea de desbaste lítico.

4.1. Perforador (Pf): Presentamos un ejemplar $(7,7 \%)$ realizado sobre una lasca interna. Se define funcionalmente por la presencia de huellas de uso sobre el lateral izquierdo de dicha lasca, que sirven para definir un ápice aguzado mediante el aprovechamiento de la morfología natural de la lasca. Aunque en realidad se trata de una lasca con retoques de uso, la inequívoca delineación morfológica en que se apoyan las huellas de utilización nos da pie para su inclusión dentro de los perforadores, si bien matizando su carácter funcional, no tipológico.

4.2. Denticulado (enc y dent): Presentamos dos piezas $(15,4 \%)$. Uno de ellos se define por la presencia en su lateral derecho de dos muescas retocadas alternas, mientras que el otro presenta en el lateral derecho retoques abruptos directos y profundos, que definen un dorso abatido; por lo que se trata de un útil compuesto, ya que en su lado izquierdo aparecen dos muescas retocadas simples. Ambos sobre lascas internas.

4.3. Lascas y láminas retocadas. Abrimos este apartado para incluir aquellos útiles considerados como tales en función de la presencia de alguna modificación secundaria o retoque, pero que no presentan rasgos que permitan su inclusión dentro de algún grupo tipológico definido. Hacemos así referencia al caso de los retoques de uso que no entran en la tipología de Laplace, pero que son una realidad a la hora de plantear la existencia de útiles funcionales.

4.3.1. Lascas con retoques simples (LsRS): Un ejemplar realizado sobre una lasca interna con fractura proximal y talón abatido que representa retoque simple directo y marginal sobre su lateral izquierdo.

4.3.2. Láminas con retoques de uso ( $\mathrm{LmRU})$ : Se trata de dos hojas, una está fracturada tanto en el lado distal como en proximal, y otra sólo distalmente. Presentan retoques o huellas de utilización sobre su lateral derecho, aprovechando así el largo filo recto y agudo que presentaría la lámina tras su extracción, sin necesidad de modificación secundaria. En este caso la modificación es efecto del uso y no el agente que busca facilitar la utilización de la pieza para una determinada tarea.

El total analizado se completa con la presencia de un fragmento de anfibolita pulimentado del que, por presentar fractura distal, no podemos precisar su descripción, pudiendo tratarse de un hacha o una azuela. 


\section{C.- Inventarios porcentuales}

INVENTARIO PORCENTUAL SOBRE EL TOTAL DE LA INDUSTRIA (Fig. 8)

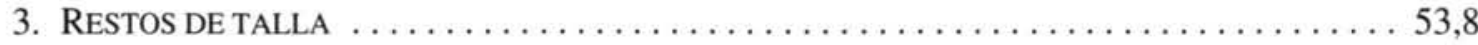

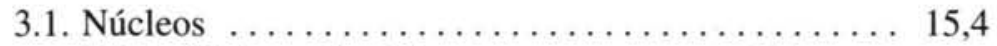

3.1.1. Núcleos discoides $\ldots \ldots \ldots \ldots \ldots 7,7$

3.1.2. Núcleos para hojas ........ 7,7

3.2. Lascas

3.2.1. Lascas de descortezado ....... 15,4

3.2.2. Lascas internas . . . . . . . . 23,1

4. ÚTILES 46,2

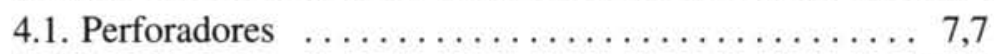

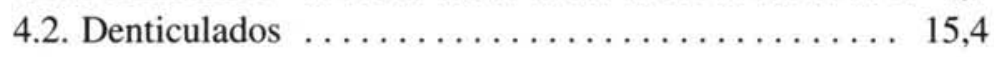

4.3. Lascas y láminas retocadas $\ldots \ldots \ldots \ldots \ldots \ldots .23,1$

4.3.1. Lascas de retoque simple $\ldots \ldots \ldots 7,7$

4.3.2. Láminas de retoque de uso . . . 15,4

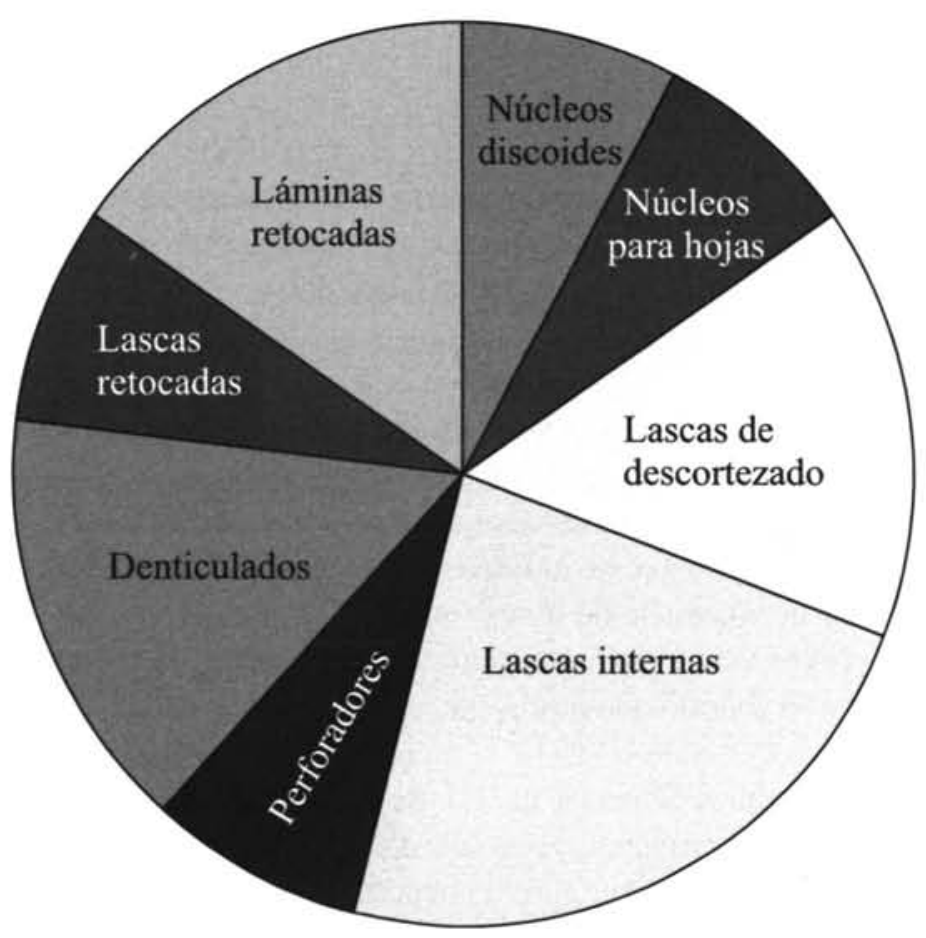

Fig. 8. Industria lítica tallada 


\section{INVENTARIO PORCENTUAL POR GRUPOS}

3. Restos de talla . . . . . . . . . . . . . . . . . . . . . . . . . . . 100

3.1. Núcleos ..................... 28,6

3.1.1. Núcleos discoides $\ldots \ldots \ldots \ldots . .50$

3.1.2. Núcleos para hojas ...........50

3.2. Lascas ........................ 100.. 71,4

3.2.1. Lascas de descortezado .........40 40 3.2.2. Lascas internas ............6 60

4. ÚTILES

4.1. Perforadores $\ldots \ldots \ldots \ldots \ldots \ldots \ldots \ldots \ldots \ldots \ldots \ldots, 16,7$

4.2. Denticulados ...................... 33,3

4.3. Lascas y láminas retocadas $\ldots \ldots \ldots \ldots \ldots \ldots 100 . .50$

4.3.1. Lascas de retoque simple $\ldots . .33,3$

4.3.2. Láminas de retoque de uso $\ldots .666,7$

\section{D.- Materiales}

Los materiales empleados para la talla pueden definirse por su buena calidad, facilidad para tallar, y por su fractura limpia y cortante. De tal manera la industria lítica tallada se ha realizado sobre material silíceo: cinco piezas sobre sílex propiamente dicho $(38,5 \%)$ y ocho sobre caliza oolítica silicificada $(61,5 \%)$ (Fig. 9). La única pieza pulimentada ha sido trabajada sobre una roca volcánica, la anfibolita.

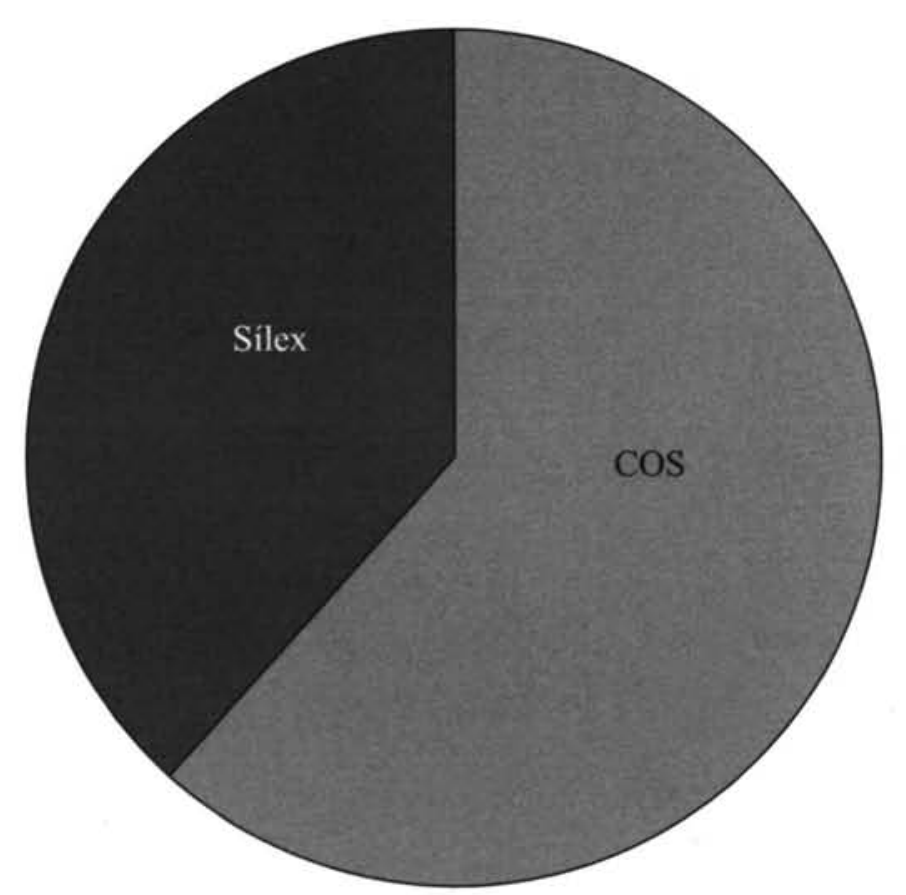

Fig. 9. Materiales industria tallada 


\section{E.- Rodamiento}

Del total de la industria analizada, tan sólo dos piezas presentan un grado de rodamiento que hemos definido como medio, queriendo con ello indicar un cierto desgaste de las aristas y de la silueta general de la pieza, pero sin que en ningún momento haya dificultades para su identificación tipológica. Esta alteración, al tratarse de unas piezas depositadas en un lugar teóricamente cerrado, pudo deberse a fenómenos mecánicos de alteración previos a la deposición dentro del dolmen, o bien a fenómenos postdeposicionales que desconocemos. Se trata de una lasca interna y otra con retoques simples, y de ambas desconocemos el lugar exacto de su hallazgo; lo que viene a incidir en esta falta de precisión a la hora de explicar dicha alteración en la morfología inicial de la pieza.

\section{F.- Cómputo general de restos de talla y útiles}

De toda la industria lítica analizada el $53,8 \%$ corresponde a restos de talla; de ellos el $28,6 \%$ son núcleos y el $71,4 \%$ lascas y láminas sin retocar. De esta manera, el $46,2 \%$ pertenece al conjunto de útiles. Podemos decir que ambos bloques están representados con bastante homogeneidad, siendo el peso de los útiles casi el de la mitad del conjunto; dato que no deja de ser significativo ya que, generalmente, éstos se encuentran en desventaja en relación a los restos de talla (Fig. 10).

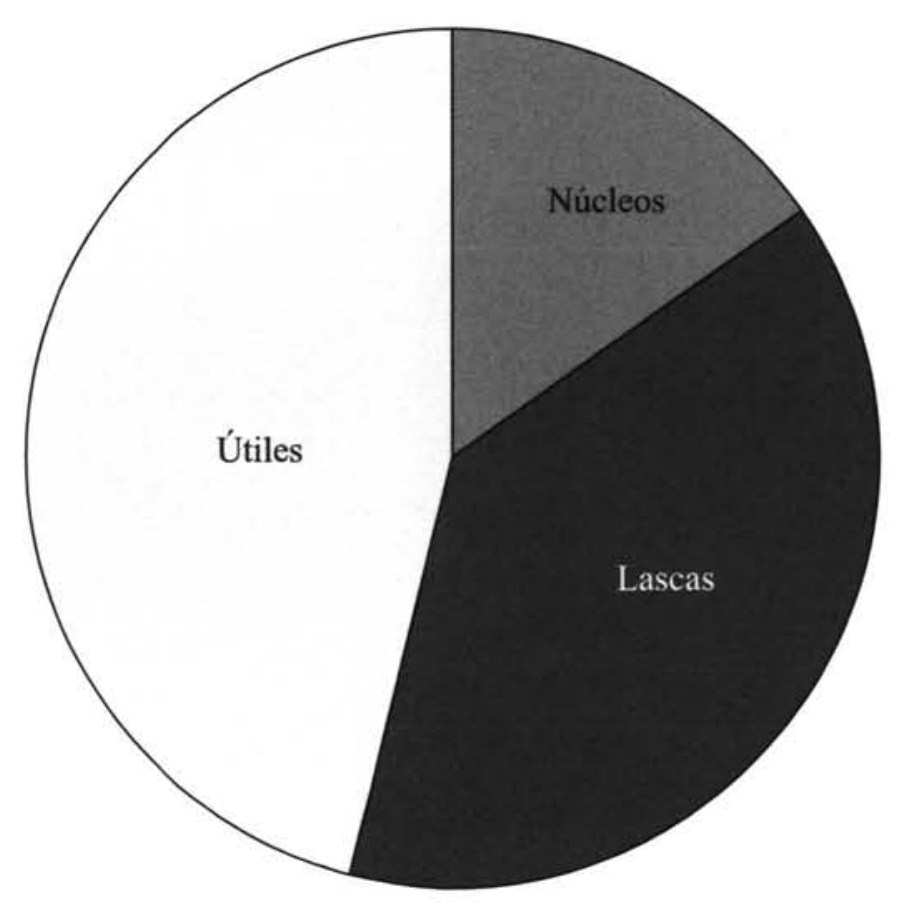

Fig. 10. Restos de talla y útiles 


\section{G.- Talones}

Del total de los talones reconocibles, en 11 piezas no fracturadas, la mayoría se corresponden a talones lisos, incluyendo los lisos corticales y los puntiformes, seguidos por los talones abatidos, 3 , que pertenecen en su totalidad a piezas con fractura proximal:
Lisos (I)
4.. $33,4 \%$

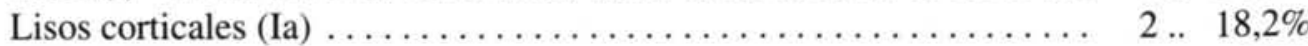

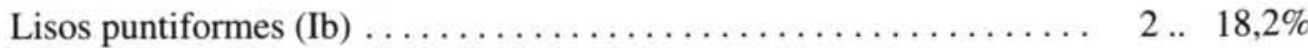

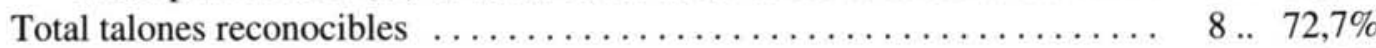
Abatidos (V) . . . . . . 27,3\%

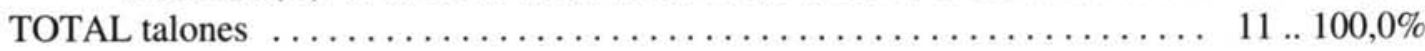

Dentro del conjunto tallado, las dos piezas que faltan por recontar corresponden a núcleos. Las lascas de descortezado presentan talones abatidos por fractura proximal, o puntiformes, dato éste un tanto curioso dado el carácter inicial de la talla. Las internas tienen sobre todo talones lisos y lisos corticales, que se pueden relacionar con una talla de apoyos sucesivos para lascados similares a los que presenta el núcleo discoide ya comentado (Fig. 11).

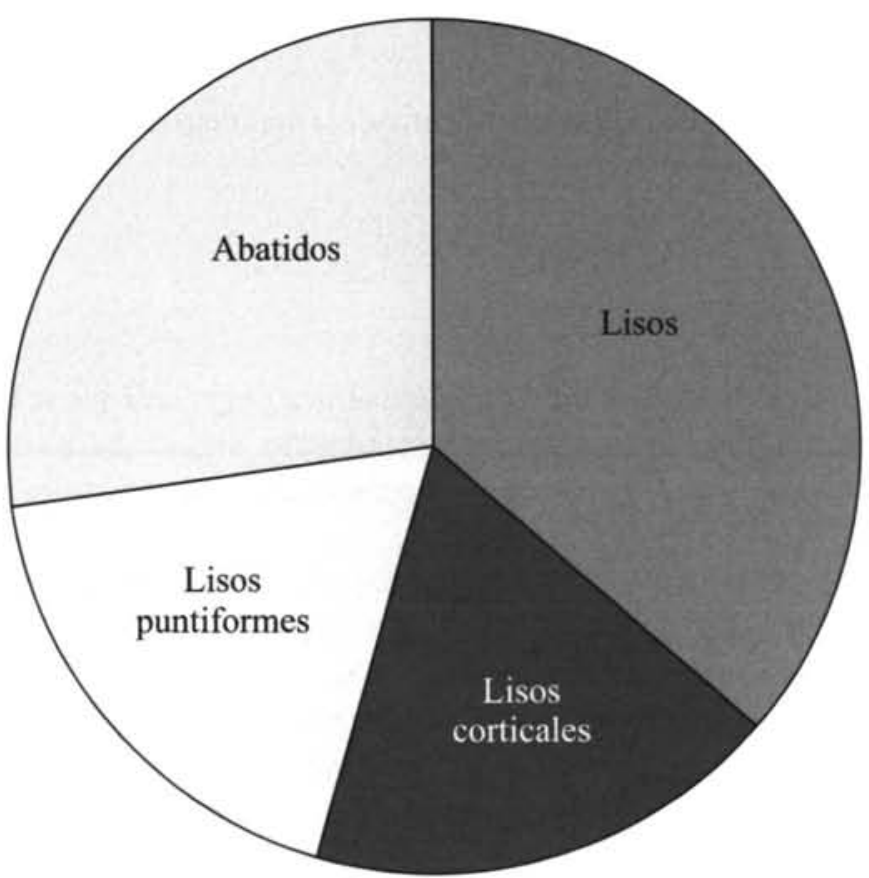

Fig. 11. Talones restos de talla 


\section{H.- Tipometría}

Con respecto a la anchura de las hojas, tanto retocadas como sin retocar, debemos señalar que son todas estrechas, ya que oscilan entre 10 y $14 \mathrm{~mm}$. Destaca una pieza que presenta $25 \mathrm{~mm}$ de anchura, lo que nos habla de una tendencia progresiva hacia el ensanchamiento de las hojas. En el Neolítico Medio y Final la constante marca la presencia de hojas de tendencia microlítica (inferiores a $14 \mathrm{~mm}$ ), mientras que durante el Cobre Antiguo y Pleno se invierte esta tendencia, apareciendo las hojas más espesas y anchas, e iniciándose con ello el camino de la desmicrolitización.

En relación a las secciones de las hojas, éstas son muy estrechas $(3 \mathrm{~mm})$ en las hojas de menor anchura, para alcanzar los $9 \mathrm{~mm}$ en la hoja ya mencionada de tendencia macrolítica, que es la que ha sido utilizada en bruto, presentando por ello las huellas de retoque de uso.

Aplicamos el modelo tipométrico de Bagolini (Bagolini 1968) para las piezas no fracturadas, aunque aportando con ello un dato meramente descriptivo, ya que este modelo fue definido para un conjunto no inferior a las 500 piezas.

Piezas de muy pequeño tamaño:

1 microlasca $\ldots \ldots \ldots \ldots \ldots \ldots \ldots \ldots \ldots$

Piezas de pequeño tamaño:

2 lascas pequeñas $\ldots \ldots \ldots \ldots \ldots \ldots \ldots \ldots \ldots$

3 lascas pequeñas y anchas $\ldots \ldots \ldots \ldots \ldots, 50,0 \%$

Total 6 ........................ 100,0\%

Estos datos nos aproximan a una homogeneidad dentro de la tipometría de los productos de talla, marcando la presencia de piezas de pequeño tamaño.

\section{I.- Análisis de los útiles por grupos culturales}

Debido a la escasa entidad de los útiles y de la industria lítica en general que se ha recogido en el dolmen de El Palomar, poco podemos atrevernos a decir en este aspecto. Siguiendo la atribución de asociaciones de útiles a diversos grupos culturales, que ya hemos presentado en varios trabajos ${ }^{6}$, podemos delimitar la presencia de:

- Un perforador, que se puede encuadrar generalmente dentro de los definidos como útiles del sustrato y que hace referencia a aquellos elementos-útiles de larga tradición desde momentos paleolíticos. Son piezas que perviven como útiles domésticos de largo alcance. En este caso se trata de un perforador funcional en el que la función se supedita a las rígidas técnicas y modelos tipológicos de épocas anteriores.

- Las muescas y denticulados se definen dentro de un grupo con entidad propia. En este caso se trata del segundo conjunto representado, siendo útiles muy numerosos en todas las épocas, vinculados a labores agrícolas o del trabajo de la madera.

-El conjunto con más peso corresponde a las lascas y láminas retocadas, siendo las más representativas las que presentan los negativos de la utilización o huellas de uso, y que se corresponde a hojas de talla a presión que han sido utilizadas directamente.

6. María Valverde Lasanta realizó su Memoria de Licenciatura sobre La tecnología lítica del Neolítico y Calcolítico de las campiñas del Guadalquivir (Universidad de Cádiz). Vid. también 'Valverde 1993' y 'Ramos Muñoz et alii 1992: 151-177’. 
Para completar la descripción de los útiles sintetizamos analizando las lascas o láminas que les han servido de soportes, y que se corresponden con 4 lascas internas y 2 hojas.

\section{J.- Otros datos}

Fracturas. De las trece piezas talladas cinco presentan algún tipo de fractura, lo cual viene a ser un porcentaje relativamente elevado. Hay dos proximales, una distal, una lateral y otra tanto distal como proximal. Estos datos se relacionan con la alta presencia de talones abatidos y no hacen pensar en una especial selección previa a la deposición de las piezas.

Presencia / ausencia de córtex. La mayor parte de las piezas no presentan corteza, lo que podría indicar el desarrollo de una talla interna y profunda, sin embargo son seis las que cuentan con una mayor o menor presencia de corteza, tanto en la cara posterior del núcleo de tendencia discoide como en el de hojas, dentro de una morfología característica del aprovechamiento de pequeños nódulos silíceos. Dos lascas internas conservan pequeñas huellas de corteza y no debemos olvidar las ya enumeradas lascas de descortezado relacionadas con los momentos más iniciales de todo desbaste lítico, y que se han documentado cerca del esqueleto. 

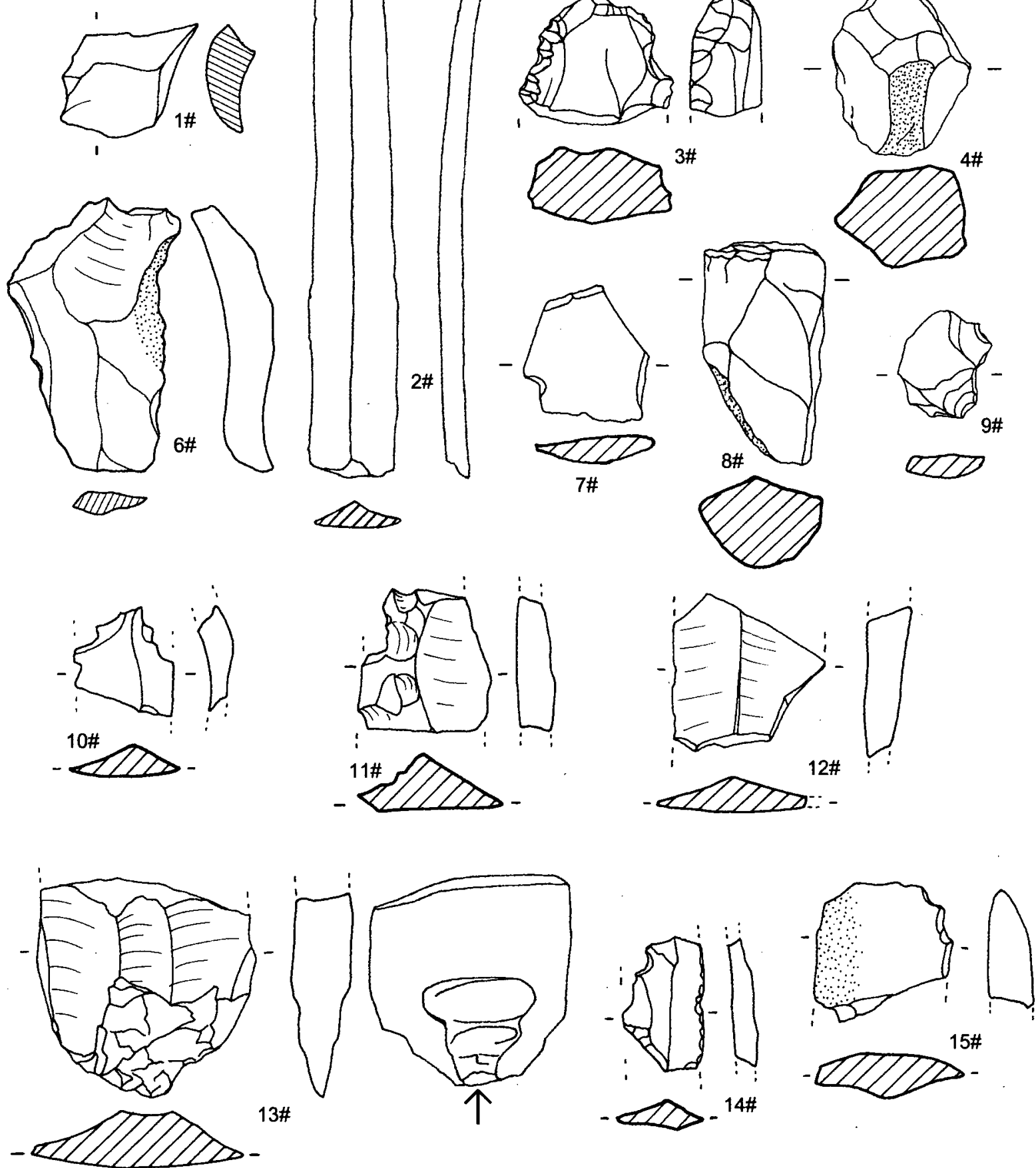

Cañada Real

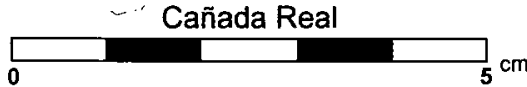

Lámina I: Industria lítica procedente del dolmen de Cañada Real 


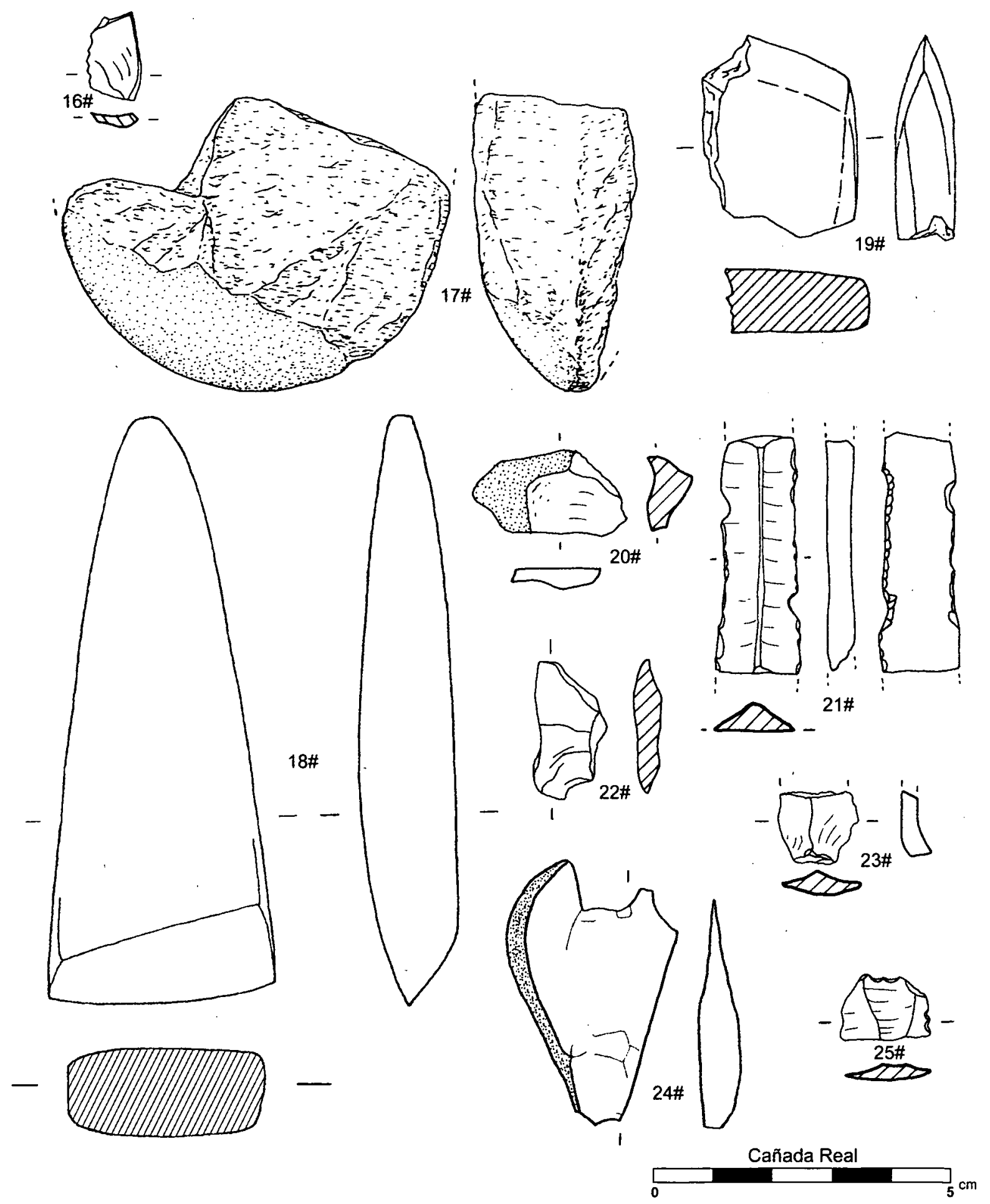

Lámina II: Industria lítica procedente del dolmen de Cañada Real

ISSN: 1133-4525 ISSN-e: 2255-3924

http://dx.doi.org/10.12795/spal.2003.i12.05

SPAL 12 (2003) 

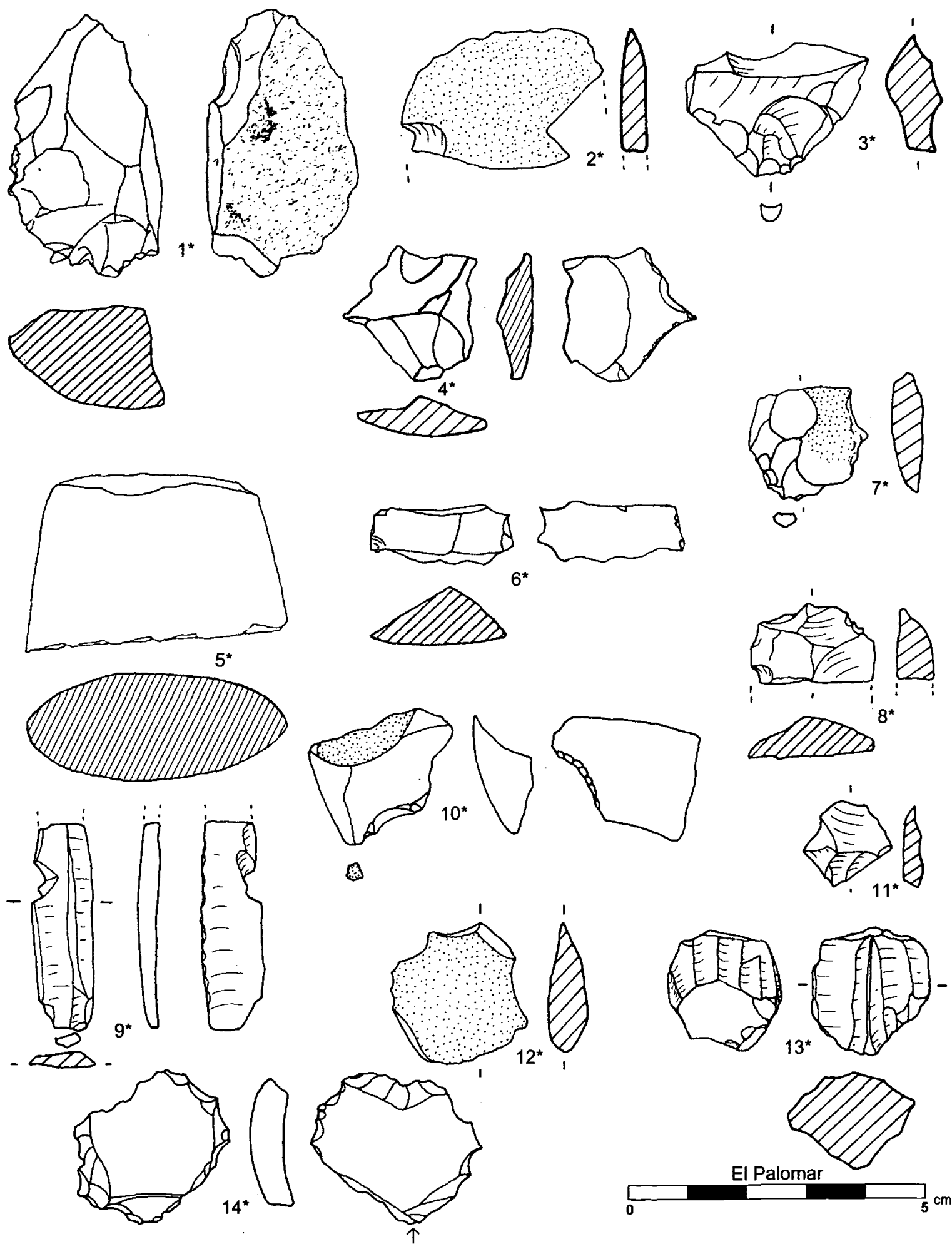

Lámina III: Industria lítica procedente del dolmen de El Palomar 


\section{ABREVIATURAS}

Rod(amiento): $\mathrm{P}=$ poco; $\mathrm{M}=$ medio.

Mat(erial): Anfi = anfibolita; $\mathrm{COS}=$ caliza oolítica silicificada; $\mathrm{Cu}=$ cuarcita; Cuar $=$ cuarzarenita; Diab $=$ diabasa; Serp $=$ serpentina; $S=$ sílex.

Ls_Lm: Ls = lasca; $\mathbf{L m}=$ lámina; $\mathrm{Nu}=$ núcleo.

I(ongitud); a(nchura); e(spesor).

S(ección): $M=$ trapezoidal; $T=$ triangular

Tal(ón): $\mathrm{I}=$ liso; $\mathrm{Ia}=$ liso cortical; $\mathrm{Ib}=$ liso puntiforme; $\mathrm{V}=$ abatido.

Fract(ura): $\mathrm{D}=$ distal; $\mathrm{L}=$ lateral; $\mathrm{P}=$ proximal.

Cort(eza): $N=$ no; $S=$ sí.

Ls_Lm_N (tipo de lasca, lámina o núcleo): Es = esquirla; $\mathrm{H}=$ hoja; $\mathrm{LsD}=$ lasca de descortezado; LsDN = lasca de desbaste de núcleo; LsI = lasca interna; LsIr = lasca interna de retoque; LsSD = lasca de semidescortezado; $\mathrm{ND}=$ núcleo discoide; $\mathrm{NDiv}=$ núcleo diverso; $\mathrm{NG}=$ núcleo globuloso; $\mathrm{NH}=$ núcleo para hojas.

RLD (retoque lateral derecho); RLI (retoque lateral izquierdo); RD (retoque distal); RP(retoque proximal): $\mathrm{A}=$ abruptos $; \mathrm{C}=$ continuos $; \mathrm{D}=$ directos $\mathrm{I}=$ inversos; $\mathrm{M}=$ marginales $\mathrm{P}=$ profundos; $\mathrm{S}=$ simples; $\mathrm{U}=$ uso.

Otros: $2 \mathrm{mu}-\mathrm{r}=2$ muescas retocadas $; 2 \mathrm{mu}-\mathrm{rAl}=2$ muescas retocadas alternas; mu- $\mathrm{s}=$ muesca simple; $\mathrm{LmRA}$ = lámina con retoque abrupto; $\mathrm{LmRU}=$ lámina con retoque de uso; $\mathrm{LsRS}=$ lasca con retoque simple; $\mathrm{Pf}=$ perforador; Rasp lat $=$ raspador lateral; $\mathrm{RS}+\mathrm{A}=$ retoque simple+abrupto.

\section{BIBLIOGRAFÍA}

AA.VV. (1982): Arqueología 81, Memoria de las actuaciones programadas en el año 1981. Ministerio de Cultura. Dirección General de Bellas Artes, Archivos y Bibliotecas. Subdirección General de Arqueología y Etnografía: 122.

BAGOLINI, B. (1968): Ricerche sulle dimensioni dei manufatti litici prehistorici non ritoccati, Annali dell'Università di Ferrara.

CABRERO GARCÍA, R. (1986): "Informe preliminar sobre las excavaciones arqueológicas realizadas en el yacimiento de Amarguillo II (Los Molares, Sevilla)”, Anuario Arqueológico de Andalucía II: 180-185.

— (1987): "El poblado de la Edad del Cobre denominado Amarguillo II (Los Molares, Sevilla). Informe preliminar tras la excavación sistemática de 1987', Anuario Arqueológico de Andalucía II: 276-277.

- (1988): El fenómeno megalítico en Andalucía Occidental, Tesis Doctoral. Universidad de Sevilla, 4 tomos (microfilmada)

- (1993): "Proyecto: Amarguillo II (Los Molares). Análisis del proceso cultural operado en las sociedades agrarias de la campiña sevillana entre el IV y II milenios A.C.", Investigaciones Arqueológicas en Andalucía, 1985-1992. [Comunicaciones presentadas a las VI Jornadas de Arqueología Andaluza celebradas en Huelva del 25 al 29 de enero de 1993], Dirección General de Bienes Culturales, Huelva: 367-371.

CABRERO GARCÍA, R. y otros (1991): "Estudio de la Campiña sevillana en la Edad del Cobre". Plan Andaluz de Investigación. Inventario de grupos de investigación y desarrollo tecnológico. Dirección General de Universidades e Investigación, Sevilla, II: 901. 
CABRERO GARCÍA, R.; RUIZ MORENO, M.T.; CUADRADO MARTÍN, L.B.; SABATÉ DÍAZ, I.; MALGOSA MORERA, A.; VALVERDE LASANTA, M.; SAFONT MASS, S.; GONZÁLEZ RODRÍGUEZ, M.; SUBIRÁ DE GALDÁCANO, M.E.; GONZÁLEZ VILCHES, M.C.; PASCUAL MARTÍNEZ. E. y BARDERA SOLER DEMORELL, R.(1993): “El poblado metalúrgico de Amarguillo II en Los Molares (Sevilla) y su entorno inmediato en la campiña: últimas analíticas realizadas", Anuario Arqueológico de Andalucía II: 131-141.

CABRERO GARCÍA, R.; OLIVA ALONSO, D.; MALGOSA MORERA, A.; SAFONT MAS, S.; RUIZ MORENO, M.T.; SUBIRÁ DE GALDÁCANO, M.E.; SABATÉ DÍAZ, I. y BARDERA SOLER DE MORELL, R. (1995): “Arqueometría antropológica en el sepulcro megalítico de El Palomar: Contribución al conocimiento histórico de la campiña sevillana", Spal 4: 69-79.

CABRERO GARCÍA, R.; RUIZ MORENO, M.T.; SABATÉDÍAZ, I. y CUADRADOMARTÍN, L.B. (1996): "Artefactos de tradición neolítica en sociedades prehistóricas de la provincia de Sevilla: Cronología y cambio cultural", I Congrés del Neolitic a la Península Ibérica, Gavá-Bellaterra (Barcelona, 1995). Rubrigatum I, Vol. 1: 191-200.

CARRIAZO Y ARROQUIA, J. de M. (1974): Protohistoria de Sevilla, Sevilla.

NIETO, J. M.; NOCETE, F.; SÁEZ, R.y FRANCO, F. (2002): "Cambios mineralógicos en restos óseos en función de las condiciones de pH del suelo", Geogaceta 31: 189-192.

PECERO ESPÍN, J. C. y GUIJO MAURI, J. M. (1998): "Evidencias Osteológicas de la Necrópolis de La Traviesa: Caracterización Antropológica y Tafonómica”, L. GARCÍA SANJUÁN(Editor), La Traviesa. Ritual Funerario y Jerarquización Social en una Comunidad de la Edad del Bronce de Sierra Morena Occidental, Spal Monografías I: 191-216.

RÁMOS MUÑOZ, J.; VALVERDE LASANTA, M.; ALMAGRO BLÁZQUEZ, A. y ROMEROSÁNCHEZ, J.L. (1992): "Tecnología lítica de las Edades del Cobre y Bronce en la marisma del Cuervo (Jerez de la Frontera, Cádiz)", Spal 1: 151-177.

VALVERDE LASANTA, M. (1993): El taller de Cantarranas (El Puerto de Santa María - Cádiz). Un ejemplo para la transición Neolítico Calcolítico, Servicio de Publicaciones, Universidad de Cádiz. 